\title{
ESTRUTURA PRODUTIVA DE MINAS GERAIS (MG): UMA ANÁLISE MICRORREGIONAL PARA OS ANOS DE 2007 E 2014
}

\section{FÁBIO HENRIQUE DOS ANJOS}

Mestrando no Instituto de Ciências Sociais Aplicadas da Universidade Federal de Alfenas, Campus Varginha - ICSA-UNIFAL/MG.

THIAGO CALIARI SILVA

Professor Adjunto no Instituto de Ciências Sociais Aplicadas da Universidade Federal de Alfenas, Campus Varginha - ICSA-UNIFAL/MG.

MARIELLE JACINTA PEREIRA COSTA

Mestranda no Instituto de Ciências Sociais Aplicadas da Universidade Federal de Alfenas, Campus Varginha - ICSA-UNIFAL/MG.

RESUMO: Esta pesquisa objetiva verificar o atual cenário econômico-industrial de Minas Gerais pela sua dinâmica setorial e pelos seus fatores locacionais-regionais, com base nas 66 microrregiões que integram o Estado, nos anos de 2007 e 2014, analisando também a evolução dos indicadores entre os anos citados. A ideia é averiguar como o fenômeno da desconcentração produtiva, processo iniciado no Brasil ainda nos anos de 1970, tem influenciado a evolução da estrutura produtiva de MG. Entre outros resultados, pode-se destacar que Minas Gerais apresenta uma estrutura produtiva diversificada, mas que apresenta uma concentração maior das indústrias - principalmente em setores mais dinâmicos - na Região Metropolitana de Belo Horizonte e Sul de Minas.

PALAVRAS-CHAVE: Indústria; Desconcentração Produtiva; Especialização; Minas Gerais (Brasil).

ABSTRACT: This research aims to check the current economic and industrial scenario of the Minas Gerais (Brazil) State through its sector dynamics, its locational regional factors and the evolution of the indicators between the years 2007 and 2014, based on the 66 micro-regions that make up the State. The idea is to investigate how the phenomenon of productive desconcentration, which started in Brazil in the 1970s, has influenced the evolution of the productive structure of Minas Gerais (Brazil). Among other results, it can be noted that the State has a diversified production structure, but it has a higher concentration of industries especially in the most dynamic sectors which are the Belo Horizonte metropolitan area and southern Minas Gerais.

KEYWORDS: Industry; Productive Deconcentration; Specialization; Minas Gerais (Brazil).

ÁREA TEMÁTICA - ÁREA 1: Dinâmicas industriais setoriais e dos sistemas de produção.

Classificação JEL: R12, L16.

\section{INTRODUÇÃO}

A indústria foi o motor do crescimento econômico brasileiro principalmente no período entre 1950 a 1980 quando o país constituiu uma estrutura industrial relativamente integrada e impulsionada pelo 
mercado doméstico (SARTI; HIRATUKA, 2011), num processo em que se verifica maior especialização produtiva e elevação da concentração industrial nas capitais brasileiras (SAMPAIO, 2011). Para Cano (2008) essa dinâmica de concentração econômica regional no Brasil se acentua desde o início do século XX, a destacar o estado de São Paulo ${ }^{1}$.

Ao tratar do Estado de Minas Gerais, é possível observar que sua economia experimentou o “boom” da industrialização na década de 1970 (PDMI, 2003). Sua matriz mineradora, sem dúvida, colocou o Estado em posição favorável para responder às iniciativas da industrialização (PAULA, 2001). Com o desempenho econômico acima da média nacional, Minas Gerais cresceu a expressivas taxas, impulsionadas pelo volume de investimentos que se instaurou em seu território, quando a expansão da economia brasileira e o início da desconcentração industrial ganham força, além da conjuntura internacional favorável (PMDI, 2003).

De acordo com Nogueira Júnior (2010) Minas se beneficiou enormemente da desconcentração industrial brasileira. Porém, dados do PMDI (2003) explicam que este "surto" de desenvolvimento não foi espontâneo. Ao contrário, foi induzido pela ação do próprio Estado que, desde meados dos anos 60, havia instituído uma inovadora estrutura de planejamento para o desenvolvimento. Nogueira Júnior (2010) relata que a indústria mineira vem aumentando sua participação na indústria brasileira gradualmente, e os ganhos se concentram especialmente no complexo metal-mecânico da região central do Estado, reforçando a tradição da especialização de Minas no setor de bens intermediários.

Em uma análise nacional, a indústria passa a se desconcentrar do Estado de São Paulo na década de 1970 em virtude dos efeitos de transbordamento - que compreendem a expulsão das atividades econômicas como consequência de fatores que inviabilizam o processo produtivo, podendo considerar: os custos de transportes, impostos regionais e problemas de infraestrutura, responsáveis por dispersar atividades específicas e reorientá-las espacialmente (DINIZ, 2010).

A década de 80 ou “década perdida" (CANO, 2008) teve uma elevada instabilidade nas principais variáveis macroeconômicas do país (ERBER, 2001). A crise fiscal e financeira do EstadoNação representou uma ruptura na condução do processo de expansão. Com a crise da dívida externa, o Brasil teve de rever a sua estratégia de desenvolvimento. Esta estratégia representava uma restrição ao crescimento, já que os saldos comerciais eram utilizados para o pagamento da dívida (SAMPAIO, 2011).

As políticas macroeconômicas de caráter restritivo na década de 90 também não viabilizaram uma trajetória elevada de crescimento do PIB, tampouco da taxa de investimento que possibilitasse um círculo virtuoso para o país (SAMPAIO, 2011). Sarti e Hiratuka (2011) reforçam que a adoção de sucessivas políticas econômicas estabilizadoras resultaram em perda relativa do dinamismo industrial em todo o País. Minas Gerais, por exemplo, chegou ao final do século XX com sinais de perda da intensidade econômica.

Fernandes e Oliveira (2010) explicam que embora tenham sido importantes os investimentos na economia mineira na década de 1970 para o avanço da indústria, os resultados não foram tão efetivos para sua manutenção. Muitos movimentos de deslocamento produtivo das empresas apenas transferiram suas unidades produtivas para Minas Gerais a fim de usufruírem dos incentivos concedidos pelo governo, mantendo a sede de administração no principal centro industrial do país (São Paulo), enfraquecendo, assim, os efeitos internos de investimentos. Por essa razão, a economia mineira teria se mantido altamente dependente do comportamento da economia nacional, o que explicaria sua elevada sensibilidade aos ciclos econômicos, crescendo com maior velocidade nas fases de expansão e contraindo-se com mais vigor nas de retração.

A ausência de políticas públicas por parte do Governo Federal estimulou os localismos no Brasil. O poder local passa a promover uma série de incentivos fiscais para fins de atração de investimentos produtivos e comerciais, conformando uma verdadeira "guerra fiscal” (SAMPAIO, 2011). Cano (2008) expõe que muitos governos locais, como medida de defesa, se lançaram na infeliz empreitada da "guerra fiscal” submetendo-se a verdadeiros leilões de localização industrial promovidos para grandes empresas.

A ausência de articulação entre o local e o nacional fica patente quando determinadas regiões passam a crescer a taxas muito mais elevadas que outras. Dessa forma, perdem-se os nexos inter-

\footnotetext{
${ }^{1}$ O autor faz recordar que em 1929, antes do advento dessa trajetória, a capital Paulista já concentrava 37,5\% da produção industrial brasileira de transformação, cifra que com a industrialização e integração do mercado nacional chegaria ao máximo de 58,1\% em 1970 (CANO, 2008).
} 
regionais, acentuando uma verdadeira fragmentação dos espaços e aumentando heterogeneidades estruturais, sociais e produtivas (SAMPAIO, 2011). Sabe-se que este cenário não é muito diferente para a economia Mineira. O Estado possui grande discrepância na produção e na renda de suas diferentes regiões em que áreas modernas e dinâmicas como o Triângulo convivem com outras deprimidas economicamente, como o Jequitinhonha/Mucuri (NOGUEIRA JÚNIOR, 2010). É a análise dessa desigualdade econômica-industrial entre as microrregiões do Estado, que se desenvolve este estudo.

Cano (2008), em seu Livro “Desconcentração Produtiva Regional do Brasil 1970-2005”, acredita que Minas Gerais foi um dos estados brasileiros que mais saiu ganhando no processo de desconcentração, e que o Brasil, como um todo, saiu perdendo, devido ao enfraquecimento do seu principal centro industrial. Logo, a perspectiva adotada neste trabalho é de que a indústria mineira, vai passar nos próximos anos, por um momento chave, em que se definirá qual o seu papel no desenvolvimento econômico brasileiro.

Sendo assim, esta pesquisa objetiva verificar o atual cenário econômico-industrial de Minas Gerais pela sua dinâmica setorial e pelos seus fatores locacionais-regionais, com base nas 66 microrregiões que integram o Estado, nos anos de 2007 e 2014, identificando, também, uma evolução dos indicadores entre os anos citados. Esta não é uma discussão sem importância, pois ao verificar as características da economia em Minas Gerais, pode-se ampliar a formulação tanto de políticas públicas mais eficientes que suavizem os efeitos de ciclos recessivos como daquelas voltadas para incentivar a modernização e diversificação de sua estrutura industrial e reduzir sua dependência de outros mercados.

\section{REFERENCIAL TEÓRICO}

\subsection{Da Desconcentração Industrial Brasileira a Estrutura Produtiva de Minas Gerais}

Desde o início dos anos 70, a problemática da desconcentração da indústria no Brasil é um "fenômeno" que vem chamando a atenção de vários pesquisadores. As principais avaliações desse movimento foram influenciadas pelos estudos acerca dos processos de "reversão da polarização", sobretudo em países desenvolvidos. Estas explicações buscavam se relacionar com o desenvolvimento das "deseconomias de aglomeração" ${ }^{2}$ provocadas pela intensificação do crescimento industrial e urbano nos grandes centros, que ocorria, em paralelo, ao surgimento de novas economias de aglomeração em outros espaços urbanos (NEGRI, 1996). Para o autor, o Brasil seria o primeiro caso de "reversão da polarização" entre os países em desenvolvimento, em que depois de décadas de um processo de concentração econômica e populacional em São Paulo, começava-se a assistir uma tendência inversa.

Fato é que a partir destas transformações econômicas, o movimento se intensificou no sentido da desconcentração produtiva, em dois sentidos: um, dentro do próprio Estado de São Paulo, no sentido metrópole-interior; e outro, no sentido de São Paulo em direção ao restante do país (CANO, 2008) cabendo destacar o papel de uma "guerra fiscal" que foi intensificada por todo o território nacional na busca por grandes indústrias, sinônimos de desenvolvimento (SAMPAIO, 2011). Davam-se verdadeiros leilões para a atração de grandes empreendimentos privados, em que a única certeza são os custos e as concessões por parte dos governos locais, mas não as contrapartidas das empresas (CANO, 2008).

O processo de desconcentração produtiva originalmente parecia permitir uma maior articulação e integração do sistema produtivo nacional. Apesar disso, não foi capaz de reduzir as absurdas desigualdades regionais (SOBRAL, 2007). A produção industrial e de serviços se concentrou na região Sudeste, quando o Estado de Minas Gerais teve ampliada sua participação no VTI (Valor na Transformação Industrial) nacional devido ao crescimento da exportação agrícola; e siderurgia, celulose e automobilística para o mercado interno (NEGRI, 1996).

Para Diniz (1995) todo esse processo não ocorreu de forma linear. Na primeira fase - 1970 até final dos anos 90 - o que se observou foi um movimento generalizado de desconcentração. A partir dos anos 2000 o fenômeno da desconcentração começa a ocorrer em ritmo mais acelerado (SAMPAIO, 2011). Entretanto, demonstrando uma alta concentração industrial na área compreendida entre o centro de Minas Gerais e o nordeste do Rio Grande do Sul (SOBRAL, 2007).

${ }^{2}$ Deseconomias de Aglomeração: entendida um conjunto de variáveis entre as quais se destacam os maiores custos de transportes, de terrenos, de serviços e de infraestrutura urbana, incluindo àqueles que provocavam alteração na organização da produção e na produtividade, além de maiores dispêndios de tempo com transporte, ampliação do poder sindical da classe trabalhadora, questões ambientais, deterioração das condições de vida nos grandes centros urbanos, queda na produtividade do trabalho, etc. (NEGRI, 1996). 
Esse movimento foi bastante seletivo em perspectiva setorial e espacial, sendo inclusive classificado como “desconcentração concentrada” (SOBRAL, 2007). Diniz (1995) explica que é uma tendência à reconcentração na área mais desenvolvida do país. Este movimento recente está relacionado com as mudanças tecnológicas e a reestruturação produtiva, as quais tendem a alterar os requisitos locais, especialmente daquelas atividades mais intensivas em tecnologia e conhecimento. Além disso, mudanças ideológicas e políticas que dizem respeito ao papel do Estado, a abertura da economia, em especial do Mercosul, e o processo de democratização, seguramente apontam efeitos decisivos sobre a configuração regional da indústria no Brasil, possibilitando a "reaglomeração" na região Centro-Sul ${ }^{3}$ do país.

Na década de 1970, a continuidade da integração do mercado nacional e da industrialização exigiu o aproveitamento mais intenso dos recursos naturais, implicando na montagem de grandes empreendimentos em outros estados fora da região hegemônica (VIEIRA, 2006). Em Minas Gerais âmago da pesquisa - o grande surto de investimentos industriais verificados naquela época - parte resultantes da desconcentração; parte dos esforços do Banco de Desenvolvimento de Minas Gerais (BDMG), criado em 1962, dotado de autoridade técnica avançada quando urgia o enfrentamento de desafios econômicos transcendentes para o destino do Estado (GODOY; BARBOSA; BARBOSA, 2010) - provocaram significativas alterações em sua estrutura industrial, incorporando-se a ela novos ramos produtores de bens de capital, de consumo duráveis e de diferentes produtos intermediários, propiciando o adensamento das relações industriais dentro da própria economia regional e ampliando o atendimento dos mercados interno e externo (FERNANDES; OLIVEIRA, 2010).

A década de 1980 foi marcada pela retração e estagnação do crescimento econômico, tanto no Brasil quanto em Minas Gerais (FERNANDES; OLIVEIRA, 2010), havendo, inclusive, queda na participação de Minas no Produto Interno Bruto (PIB) brasileiro (SOUZA; PEROBELLI, 2009). O processo de transformação e de dinamização da economia de Minas, iniciado nos anos 70, conheceu uma inequívoca descontinuidade a partir dos anos 80, caracterizada pela quase ausência de investimentos produtivos (FERNANDES; OLIVEIRA, 2010). No entanto, o período 80-89, foi marcado por algumas políticas estaduais - notadamente as de "guerra fiscal" - que levaram projetos privados à desconcentrarem de São Paulo, em direção à Minas Gerais - cerca de 10\% da indústria nacional de material de transporte; 7 a 10\% da metalúrgica; além da indústria de metal-mecânico e de fumo para o Estado mineiro (CANO, 2008).

Constata-se, já naquela época, no parque industrial mineiro uma forte concentração da produção em alguns poucos gêneros industriais (metalúrgica, produção de minerais não metálicos, produtos alimentares, mecânica, química, fumo, indústria extrativa) (RESENDE, 1994). Considerando essa especialização histórica e a expansão recente das indústrias de bens intermediários no Estado - cimento, metalurgia, fertilizantes - normalmente vinculadas à existência de recursos naturais, a teoria de localização industrial $^{4}$ é a que mais se ajusta a este tipo de desenvolvimento (FIGUEIREDO, 1998). Isso evidencia que, na divisão do trabalho industrial do país coube a MG o papel de supridora de boa parte dos insumos básicos às demais regiões. Essa especialização em grande parte é também explicada pela própria dotação de recursos naturais de Minas Gerais (RESENDE, 1994).

Os anos de 1990 tiveram um péssimo início, com forte recessão entre 1989 e 1993. Depois veio o Plano Real, que ancorou a política de estabilização na valorização do câmbio, na abertura abrupta da economia e no colossal avanço da dívida pública interna, criando a ilusão de que assim poderia retomar um crescimento elevado (CANO, 2008). Ademais, o governo de Minas Gerais reduziu seu papel como agente promotor e orientador do processo de desenvolvimento, não somente pelas dificuldades financeiras que passou a enfrentar, mas principalmente pelas ideias neoliberais que se tornaram predominantes na década de 1990, sobre a necessidade de afastamento do Estado da vida econômica e social dos países,

\footnotetext{
${ }^{3}$ Região Centro-Sul: Belo Horizonte / São Paulo / Uberlândia / Londrina / Maringá / Porto Alegre / Florianópolis / São José dos Campos (DINIZ, 1995, com adaptações).

${ }^{4}$ As formulações básicas da teoria da localização industrial, proposta por Weber, parte dos seguintes pressupostos: os consumidores concentram-se em pontos do espaço geográfico; o preço das mercadorias é homogêneo no espaço e os coeficientes técnicos de produção são constantes; são considerados dados os locais onde há disponibilidade de mão-de-obra e, nestes, a sua oferta é infinitamente elástica; as fontes de matérias-primas encontram-se distribuídas desigualmente no espaço, sendo divididas entre: ubiquidades - obtidas em qualquer ponto, não exercendo, portanto, impulso locacional; e matérias-primas localizadas disponíveis somente em algumas localizações, influenciando, destarte, a escolha do local; e, as tarifas de transporte das matérias-primas e dos bens finais são idênticas e constantes (FIGUEIREDO, 1998).
} 
mas, ainda assim, sua contribuição para o comportamento do setor industrial continuou fundamental, por meio de um poderoso esquema de incentivos fiscais (FERNANDES; OLIVEIRA, 2010).

A criação do Pró-Industria, ainda em 1989, um esquema de incentivos voltado predominantemente para o financiamento do capital de giro da indústria, com o objetivo de aumentar o valor agregado dos produtos, avançar na diversificação do parque industrial e estimular a utilização dos recursos naturais do Estado, só foi possível com a criação do PROIM (Programa de Indução à Modernização Industrial), em 1993. Em 1994, esses dois instrumentos seriam reunidos no FIND (Fundo de Incentivo à Industrialização), que adquiriria o status de unidade orçamentária, administrado com autonomia pelo BDMG. Em 1996, esse sistema se completaria com a criação do FUNDIEST (Fundo de Desenvolvimento de Industrias Estratégicas), o qual seria decisivo para dar novo impulso à produção de bens duráveis, notadamente do setor automotivo, e avançar alguns graus a mais na diversificação da estrutura industrial (FERNANDES; OLIVEIRA, 2010).

Em 2000, superadas as intempéries do ano anterior, a economia brasileira logrou um crescimento de 4,3\%, vindo a enfrentar, no ano seguinte, uma nova fase de baixas taxas de crescimento. Assim, em 2001, a economia mineira apresentou taxa negativa de crescimento, alguma recuperação em 2002 e reduzido crescimento em 2003. Já, entre 2004 e 2007, acompanhando a trajetória da economia brasileira, registrou-se um crescimento superior a 4\% (FERNANDES; OLIVEIRA, 2010).

É válido ressaltar que na primeira década dos anos 2000, foi observado por Firme e Simão Filho (2014), alguns pontos de crescimento industrial da produção mineira, que ocorrem de forma mais acentuada, nas regiões Sul, Central e Triângulo, e têm se destacado por seu dinamismo, atrelado à integração e expansão industrial nacional. Estas regiões localizam-se dentro ou no entorno do polígono mais industrializado e mais dinâmico do País, com melhor infraestrutura em todos os sentidos.

Tais fatores vem corroborar com a tese de "desenvolvimento poligonal” celebrada por Diniz (1993), que chama à atenção para a tendência de aglomeração da produção em volta de um centro dominante e servem como obstáculo à tendência natural do capital em buscar novas janelas de oportunidade locacional. A análise dos investimentos efetivos e previstos para o Estado de Minas, ao longo dos anos 2000, confirmam a tendência apontada acima, de acordo com Firme e Simão Filho (2014), prevendo, portanto, uma acentuação das disparidades econômicas já existentes entre as suas regiões.

No caso do Brasil, é notório que a concentração industrial prévia e a desigualdade de infraestrutura e de renda dificultam um processo de desconcentração industrial para as regiões pobres ou vazias (DINIZ, 1995). Desde o século passado que a ação do Estado Federal tem sido importante, em termos do desenvolvimento regional, condicionando a dinâmica regional brasileira por meio de investimento produtivo direto, incentivos fiscais e construção de infraestrutura, como aconteceu nos anos de 1960 com criação da SUDENE e da SUDAM. Em se tratando especificamente de Minas Gerais, temse o exemplo das microrregiões de Montes Claros e de Pirapora, que tiveram seu desenvolvimento diretamente ligados aos subsídios concedidos pelo Estado, através da SUDENE (FIGUEIREDO, 1998).

Em período recente, a existência de políticas prévias, em especial a Política Nacional de Desenvolvimento Regional (PNDR) (2007), o Programa de Aceleração do Crescimento (PAC) (2007) e a Política de Desenvolvimento Produtivo (PDP) (2008), que foram reforçadas para o enfrentamento de crise, com certeza são elementos que contam positivamente no desafio de melhorar os instrumentos de coordenação entre as várias instâncias governamentais e entre o setor público e o setor privado (SARTI; HIRATUKA, 2011). É, a partir deste período que o Brasil passa a exibir às maiores taxas de crescimento do PIB, relativamente aos períodos imediatamente anteriores, apresentando mudanças importantes na condução de políticas e melhoria do acesso ao crédito, e os programas sociais (SAMPAIO, 2011).

Ao mesmo tempo, tem-se Minas Gerais, considerada por autores como Cano (2008) e Nogueira Júnior (2010), o Estado que se beneficiou enormemente da desconcentração industrial brasileira, assumindo papel de maior destaque na produção nacional, que demonstra um claro desenvolvimento desigual entre suas diversas regiões. Essa tendência, percebida pelos autores é de contínua acentuação das disparidades, "especialmente na população industrial” (NOGUEIRA JÚNIOR, 2010, p. 148), justificando o objetivo desta pesquisa de verificar o atual cenário econômico-industrial de Minas Gerais pela sua dinâmica setorial e pelos seus fatores locacionais, com base nas 66 microrregiões que integram o 
Estado, nos anos de 2007 a 2014, identificando, também, uma evolução dos indicadores entre os anos citados. Assim, a seguir, serão apresentados os procedimentos metodológicos empregados neste trabalho.

\section{METODOLOGIA}

Este trabalho tem o objetivo de analisar o atual cenário econômico-industrial de Minas Gerais através sua dinâmica setorial e seus fatores locacionais, com base nas 66 microrregiões que integram o Estado, nos anos de 2007 a 2014, identificando ainda a evolução dos indicadores entre os anos citados. Evidencia-se que as 66 microrregiões são apresentadas com base na divisão microrregional de Minas Gerais apresentada pelo Instituto Brasileiro de Geografia e Estatística (IBGE, 2014). Vale chamar atenção ainda ao intervalo de tempo determinado que se justifica por corresponder ao período mais recente dos dados do Estado Mineiro, sendo oito anos um período razoavelmente longo para captar mudanças na estrutura produtiva das microrregiões estudadas.

A base de dados utilizada para o estudo corresponde ao emprego efetivo por atividades econômicas da Classificação Nacional de Atividades Econômicas - 2.0 (CNAE 2.0) no período informado. Sua revisão, em 2007, que resultou na versão 2.0, teve por objetivo dotar o País com uma classificação de atividades econômicas atualizada com as mudanças na estrutura e composição da economia brasileira. A CNAE 2.0, se tornou, portanto, a classificação de atividades econômicas oficialmente adotada pelo Sistema Estatístico Nacional e pelos órgãos gestores de cadastros e registros da Administração Pública do país.

Os dados brutos estão disponíveis na Relação Anual de Informações Sociais (RAIS), um importante instrumento de base de dados que integra a gestão governamental do Ministério do Trabalho e Previdência Social. Dentre as principais vantagens da RAIS pode-se destacar o nível detalhado de desagregação geográfica e setorial dos dados; em contrapartida, sua principal limitação reside na exclusiva cobertura do emprego formal.

A partir deste contexto temos que para o tratamento dos dados foram utilizadas estatística descritiva dos dados e análises de correlações das variáveis. A Tabela 1 apresenta as variáveis escolhidas para compor esta pesquisa, bem como suas correspondentes formulações.

Tabela 1: Variáveis Selecionadas

\begin{tabular}{|c|c|c|}
\hline $\mathbf{N}^{\mathbf{0}}$ & Variável & Fórmula e Definição \\
\hline 1 & $\begin{array}{l}\text { Coeficiente de } \\
\text { Especialização }\end{array}$ & $\begin{array}{c}C E S P_{J}=\sum_{i}\left(\left|e_{i j}-e_{i *}\right|\right) / 2 \\
e_{i j}=\left(E_{i j}\right) / \sum_{i} E_{i j} \text { é a distribuição do emprego na região; } \\
e_{i *}=\left(\sum_{j} E_{i j}\right) /\left(\sum_{i} \sum_{j} E_{i j}\right) \text { é a distribuição do emprego estadual. }\end{array}$ \\
\hline 2 & $\begin{array}{l}\text { Grau de } \\
\text { Industrialização }\end{array}$ & $\begin{array}{c}\text { GINDUST = POind / POurb } \\
\text { POind é o pessoal ocupado (PO) na indústria; } \\
\text { POurb é o pessoal ocupado urbano (PO total - PO agrícola). }\end{array}$ \\
\hline 3 & Analfabetismo & $\begin{array}{l}\text { ANALFAB }=\text { POanalfab } / \mathrm{PO}_{1564} \\
\text { São as pessoas ocupadas com idade entre } 15 \text { e } 64 \text { anos. }\end{array}$ \\
\hline 4 & Nível de Pobreza & $\begin{array}{c}\text { POBREZ }=\text { POmsm / POurb } \\
\text { POmsm são as pessoas ocupadas urbanas que recebem menos de um salário } \\
\text { mínimo (SM) de dezembro. }\end{array}$ \\
\hline 5 & $\begin{array}{l}\text { Massa Salarial da } \\
\text { Indústria de } \\
\text { Transformação }\end{array}$ & $\begin{array}{l}\text { MSINDTR }=(\text { MSindtr/MStotal }) * 100 \\
\text { MSindtr é a massa salarial da indústria de transformação; } \\
\text { MStotal trata-se da massa salarial industrial total. }\end{array}$ \\
\hline 6 & Mercado & $\begin{array}{l}\text { MERCADO = MSub / POurb } \\
\text { MSub é a massa salarial total menos a da agrícola. }\end{array}$ \\
\hline 7 & $\begin{array}{l}\text { Força de Trabalho } \\
\text { Especializado }\end{array}$ & $\begin{array}{l}\text { FESPEC }=\text { POesp / POurb } \\
\text { POesp é o pessoal ocupado nos subgrupos da RAIS, descritos nos resultados. }\end{array}$ \\
\hline
\end{tabular}




\begin{tabular}{|c|c|c|}
\hline 8 & $\begin{array}{l}\text { Oferta de Serviços } \\
\text { Produtivos }\end{array}$ & $\begin{array}{l}\text { SERVICOS = POservesp / POOserv } \\
\text { POservesp é o pessoal ocupado das seguintes categorias: serviços industriais de } \\
\text { utilidade pública; instituições de crédito, seguros e capitalização; comércio e } \\
\text { administração de imóveis, valores mobiliários, serviços técnicos; transporte e } \\
\text { comunicações. } \\
\text { POOserv é o pessoal ocupado total da atividade de serviços. }\end{array}$ \\
\hline 9 & Economia de Escala & $\begin{array}{l}\text { ECESCALA }=\text { P0100urb / POurb } \\
\text { PO100urb trata-se do pessoal ocupado em empresas com mais de } 100 \\
\text { funcionários. }\end{array}$ \\
\hline $\begin{array}{l}10,11 \\
\text { e } 12\end{array}$ & $\begin{array}{l}\text { Quociente Locacional: } \\
\text { três grupos da indústria } \\
\text { de transformação, } \\
\text { descritos nos } \\
\text { resultados. }\end{array}$ & $\begin{array}{c}\mathrm{Ql}_{\mathrm{ij}}=\left(\mathrm{E}_{\mathrm{ij}} / \mathrm{E}_{\mathrm{i} *}\right) /\left(\mathrm{E}_{* \mathrm{j}} / \mathrm{E}_{* *}\right) \\
\mathrm{E}_{\mathrm{ij}} \text { é o emprego no setor i e microrregião } \mathrm{j} ; \\
\mathrm{E}_{\mathrm{i} *} \text { é o emprego no setor i em todas as microrregiões; } \\
\mathrm{E}_{* \mathrm{j}} \text { é o emprego de todos os setores na microrregião } \mathrm{j} ; \\
\mathrm{E}_{* *} \text { corresponde ao emprego total no estado. }\end{array}$ \\
\hline
\end{tabular}

Fonte: BETARELLI e SIMÕES, 2011, com adaptações.

Para a realização dos cálculos e modelagens dos dados foi empregado o software estatístico denominado Ambiente R. De acordo com Mello e Peternelli (2013), o R é uma importante ferramenta de análise e manipulação de dados, modelagem linear e não linear, análise de agrupamento e correlações, além da facilidade na elaboração de diversos tipos de gráficos. Por último, para representar alguns dos dados obtidos, através de mapas microrregionais de Minas Gerais nos resultados, foi considerada a estrutura mais recente proposta pelo IBGE em 2014, como pode ser visto na Figura 1 a seguir:

Figura ${ }^{5} 1$ : Microrregiões do Estado de Minas Gerais

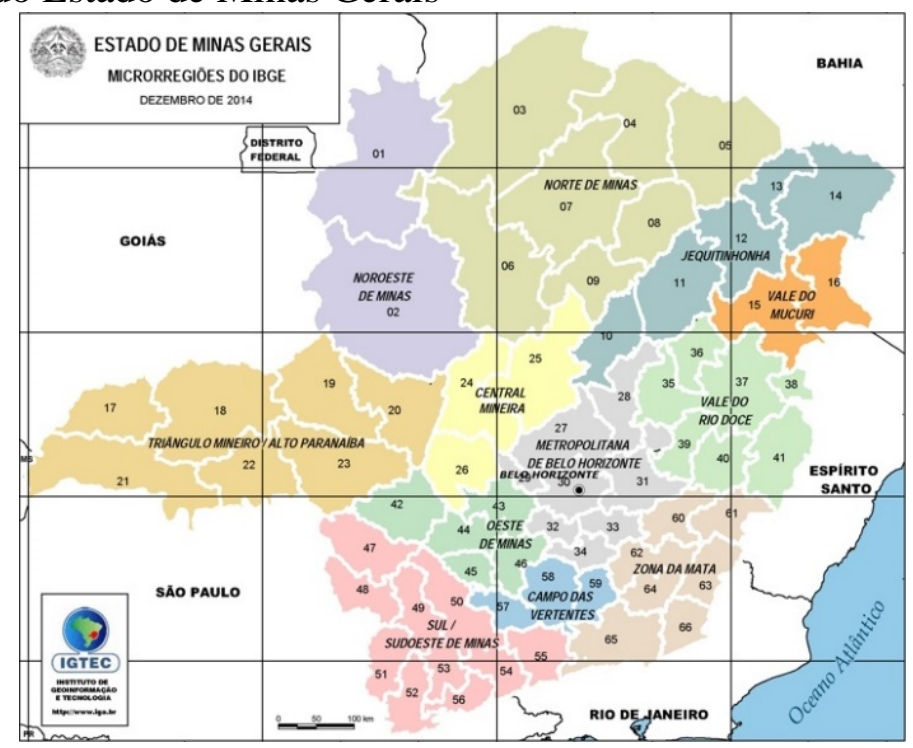

Fonte: IBGE, 2014.

\section{RESULTADOS E DISCUSSÃO}

A apresentação dos resultados está subdividida em dois momentos: o primeiro refere-se a uma exposição aprofundada das variáveis (sua conceituação teórica), uma amostra dos principais resultados obtidos em cada variável, bem como uma análise descritiva preliminar das variáveis que mostraram a

\footnotetext{
${ }^{5}$ Microrregiões de Minas Gerais: [01] Unaí; [02] Paracatu; [03] Januária; [04] Janaúba; [05] Salinas; [06] Pirapora; [07] Montes Claros; [08] Grão Mogol; [09] Bocaiúva; [10] Diamantina; [11] Capelinha; [12] Araçuaí; [13] Pedra Azul; [14] Almenara; [15] Teófilo Otoni; [16] Nanuque; [17] Ituiutaba; [18] Uberlândia; [19] Patrocínio; [20] Patos de Minas; [21] Frutal; [22] Uberaba; [23] Araxá; [24] Três Marias; [25] Curvelo; [26] Bom Despacho; [27] Sete Lagoas; [28] Conceição do Mato Dentro; [29] Pará de Minas; [30] Belo Horizonte; [31] Itabira; [32] Itaguara; [33] Ouro Preto; [34] Conselheiro Lafaiete; [35] Guanhães; [36] Peçanha; [37] Governador Valadares; [38] Mantena; [39] Ipatinga; [40] Caratinga; [41] Aimorés; [42] Pium-í; [43] Divinópolis; [44] Formiga; [45] Campo Belo; [46] Oliveira; [47] Passos; [48] São Sebastião do Paraíso; [49] Alfenas; [50] Varginha; [51] Poços de Caldas; [52] Pouso Alegre; [53] Santa Rita do Sapucaí; [54] São Lourenço; [55] Andrelândia; [56] Itajubá; [57] Lavras; [58] São João Del Rei; [59] Barbacena; [60] Ponte Nova; [61] Manhuaçu; [62] Viçosa; [63] Muriaé; [64] Ubá; [65] Juiz de Fora; [66] Cataguases.
} 
possibilidade de serem singularmente avaliadas. Cabe, portanto, ao segundo momento uma investigação delicada e correlacionada dos dados apresentados no primeiro momento desta análise.

\subsection{ESTATÍSTICA DESCRITIVA}

\subsubsection{Coeficiente de Especialização}

Figura 2: Coeficiente de Especialização das Microrregiões em Minas Gerais 2007 e 2014

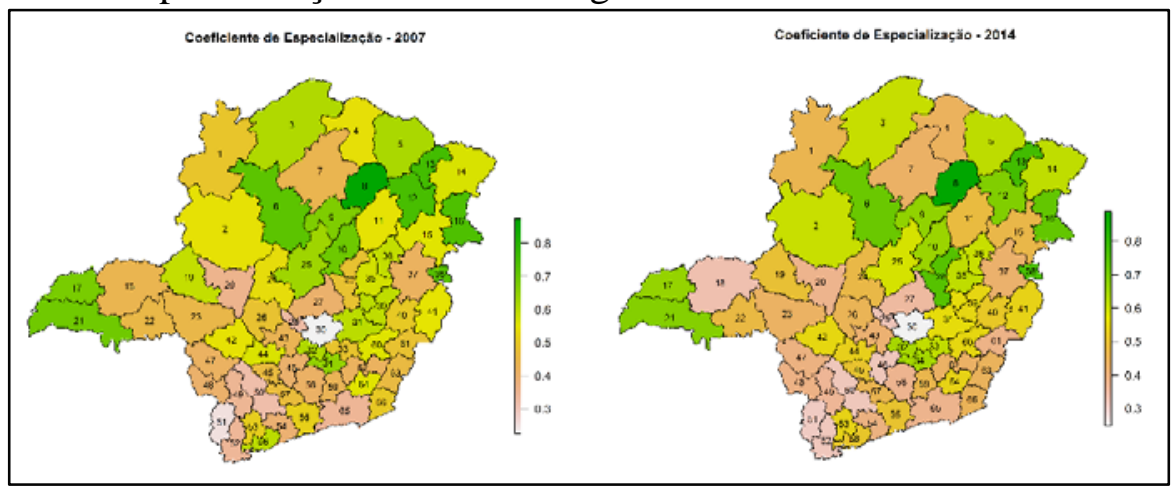

Fonte: Elaboração própria.

O coeficiente de especialização é uma medida regional, que compara a estrutura produtiva da microrregião em relação à estadual (BETARELLI; SIMÕES, 2011). As medidas regionais concentram-se na estrutura produtiva de cada microrregião, fornecendo informações sobre o nível de especialização da economia em determinado período. Para resultados iguais a zero, a mesorregião tem composição idêntica à do estado. Em contrapartida, coeficientes iguais ou próximos a um, demonstram um elevado grau de especialização ligado a um determinado setor, ou uma estrutura de mão-de-obra totalmente diversa da estrutura de mão-de-obra estadual (LIMA et al., 2006).

O Estado apresenta Belo Horizonte, Poços de Caldas, Varginha, Para de Minas, Pouso Alegre, Juiz de Fora e Alfenas como as regiões menos especializadas em 2007. Enquanto que em 2014 temos, Belo Horizonte, Poços de Caldas, Pouso Alegre, Varginha, Oliveira, Para de Minas e Uberlândia.

É importante perceber que, as microrregiões menos especializadas, e consequentemente, mais diversificadas, estão concentradas próximas a regiões polarizadas, tanto para 2007 quanto para 2014. Pará de Minas é região metropolitana de Belo Horizonte; Poços de Caldas, Pouso Alegre, Varginha e Alfenas, fazem parte da mesma mesorregião - o Sul de Minas - que demostra vantagem pela proximidade tanto da capital Mineira, como da Grande São Paulo; Juiz de Fora está situada próxima a outro grande centro econômico, o Rio de Janeiro. Oliveira torna-se a exceção, possivelmente explicada, pela proximidade da Rodovia Fernão Dias, fazendo o eixo São Paulo a Belo Horizonte. Figueiredo (1998) inclusive defende que a duplicação da Rodovia facilitou escoamento da produção, reduzindo o tempo de transporte e, portanto, os custos de transporte e de manutenção, contribuíram para a integração dos parques fabris mineiro e para o desenvolvimento regional. Imediatamente, a microrregião de Uberlândia, conforme PMDI (2011) tem alto potencial polarizador, capaz de propiciar a irradiação do acesso a serviços coletivos de escala.

Grão Mogol, Pedra Azul, Araçuaí, Nanuque, Mantena e Pirapora são as microrregiões que apresentam maior grau de especialização em 2007. Para 2014 temos o seguinte cenário: Grão Mogol, Pedra Azul, Mantena, Conceição do Mato Dentro, Nanuque e Pirapora. Atesta-se, devido aos índices, que as microrregiões os quais apresentam maior grau de especialização integram mesorregiões que já demonstram menor desenvolvimento em Minas Gerais, confirmando sua estrutura diversa da estrutura de emprego do Estado. Nogueira Júnior (2010) ao colaborar, relata que o Jequitinhonha, Vale do Mucuri, e ainda o Norte de Minas estão entre as economias mais enfraquecidas do Minas. Chama-se atenção para a microrregião de Conceição do Mato Dentro, que apesar de participar da Região Metropolitana de Belo Horizonte, é cercada por mesorregiões com economias desfavorecidas, sendo elas, Vale do Rio Doce e 
Jequitinhonha. Finalmente, ao verificar a imagem, é possível perceber, ainda que suavemente, um processo de minoração da especialização no Estado de Minas Gerais como um todo.

\subsubsection{Grau de Industrialização}

Figura 3: Grau de Industrialização das Microrregiões em Minas Gerais 2007 e 2014

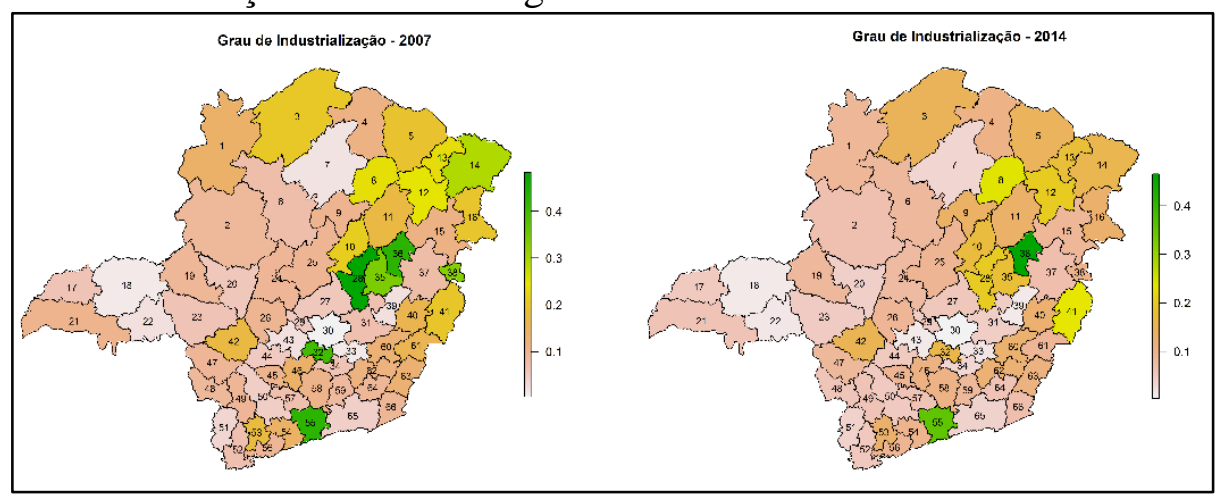

Fonte: Elaboração própria.

Associado às economias de urbanização (no sentido que apresenta um mercado local significativo de compradores e de vendedores), o grau de industrialização provoca maiores efeitos de encadeamento "para frente" e "para trás” (BETARELLI; SIMÕES, 2011). Os efeitos de "encadeamento para frente" representam os movimentos de uma indústria em induzir o desenvolvimento potencial de outras indústrias, em atividades praticadas nos estágios posteriores do processo produtivo. Já os efeitos "para trás” representam os movimentos que puxam o desenvolvimento de outras indústrias, estimulando à procura de produtos fabricados por outras atividades, situadas em estágios precedentes ao processo de produção em si. Assim, a interpretação que está sendo dada é a de que o maior grau de industrialização permita um maior desenvolvimento das microrregiões, induzindo ainda aumentos na produtividade total (FOCHEZATTO; VALENTINI, 2010).

Ao que se refere às suas variáveis, verifica-se uma relação inversamente proporcional, sabendo que quanto menor o pessoal ocupado na indústria e maior a população ocupada urbana, o índice apresenta valores mais próximos a zero. Ou ainda, mantido o número de pessoal ocupado na indústria e aumentando o pessoal ocupado urbano, os valores ainda estarão próximos a zero. Imediatamente, cenários como descritos foram percebidos em situações que as microrregiões apresentam altos índices de massa populacional. Em 2007, Belo Horizonte, foi a microrregião com o menor índice de Grau de Industrialização. Isso mostra a pouca dependência do setor industrial na microrregião analisada, além de maior dinamicidade e boa relação com o do setor de serviços. Em BH, fica óbvia a comparação entre as variáveis, pois é desconforme o número do pessoal ocupado urbano quando comparado a população ocupante da indústria.

O mesmo cenário pode ser visto em nove dos dez índices com menor valor, em que, além de Belo Horizonte, apresentam altos índices populacionais, sendo elas: Uberlândia, Montes Claros, Uberaba, Ipatinga, Divinópolis, Poços de Caldas, Juiz de Fora, Varginha. Já, a microrregião de Ouro Preto segundo colocado - torna-se a exceção entre os dez índices mais baixos apresentados. Parte histórica de Minas Gerais, a região apresenta baixo valor de pessoal ocupado na indústria e baixo valor de pessoal ocupado urbano. Figueiredo e Diniz (2000) entende o fato da pouca industrialização pela ausência de entorno agrícola robusto e de poucas condições físico-territoriais.

Ao que corresponde o ano de 2014, foram mínimas as mudanças nos índices do Grau de Industrialização das microrregiões: Belo Horizonte, Uberlândia, Ipatinga, Divinópolis, Uberaba, Ouro Preto, Conselheiro Lafaiete, Montes Claros, Juiz de Fora, Poços de Caldas. Destaca-se, que nove entre as dez microrregiões, são as mesmas que apresentaram os menores índices em 2007. A mudança mais significativa ocorreu com a saída de Varginha, e a entrada de Conselheiro Lafaiete, que pertencente à mesorregião Metropolitana de Belo Horizonte vem se mostrando mais dinâmica e atrativa às indústrias ao longo dos anos. 
Entre as microrregiões que apresentaram os maiores índices de grau de industrialização, em 2007, tem-se: Conceição do Mato Dentro, Peçanha, Andrelândia, Itaguara, Guanhães, Mantena, Almenara, Araçuaí, Grão Mogol, Pedra Azul. Para 2014, são ínfimas as mudanças, tendo saído as microrregiões de Mantena e Almenara, dando lugar a Aimorés e Diamantina, como vemos a seguir: Peçanha, Andrelândia, Grão Mogol, Aimorés, Araçuaí, Conceição do Mato Dentro, Guanhães, Pedra Azul, Diamantina, Itaguara. Vale lembrar que, por se tratar de relação inversa de variáveis, os índices mais altos indicam uma menor atratividade no que se refere às economias de urbanização.

\subsubsection{Analfabetismo}

Figura 4: Índice de Analfabetismo em Minas Gerais 2007 e 2014

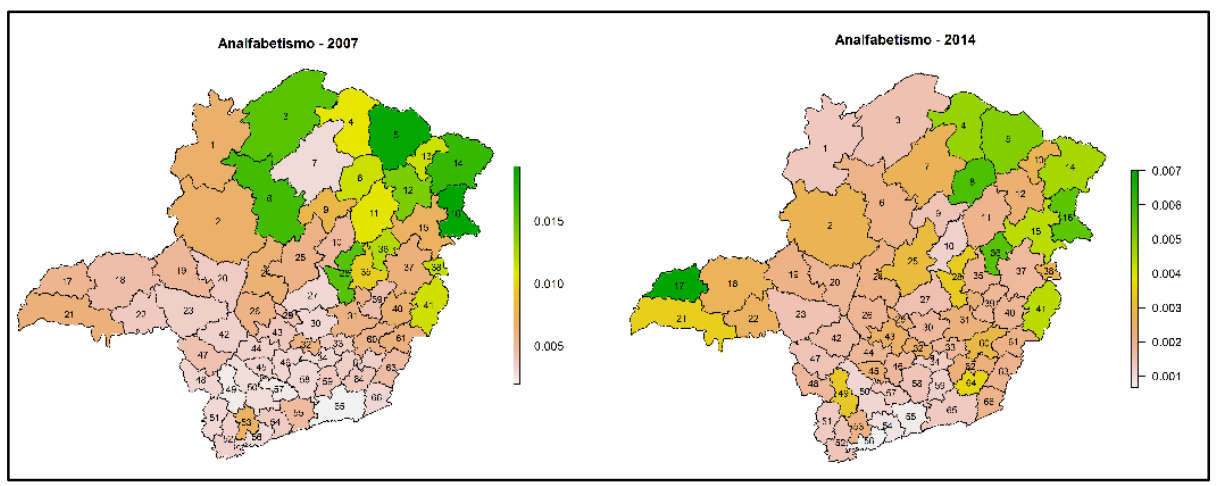

Fonte: Elaboração própria.

Caracteriza-se por representar a baixa qualificação da força de trabalho de determinada microrregião e atua como um fator desaglomerativo para as atividades intensivas em trabalho qualificado. Contudo, para setores não demandantes de qualificação, essa variável pode representar uma fonte de atração. Altos índices de analfabetismo somados a altos índices de níveis de pobreza tendem a induzir deseconomias urbanas (BETARELLI; SIMÕES, 2011).

O analfabetismo, do ponto de vista das variáveis “pessoal ocupado analfabeto" e "pessoal ocupado entre 15 e 64 anos”, propende-se a indicar que quanto mais próximo de zero o valor do índice da microrregião menor é a ocorrência de pessoal ocupado analfabeto dentro da faixa etária estabelecida. Em 2007, MG apresentou a seguinte situação dentre os menores índices de analfabetismo: Juiz de Fora, Alfenas, Lavras, Varginha, Itajubá, Montes Claros, São Joao Del Rei, Belo Horizonte, Conselheiro Lafaiete, Sete Lagoas. Para 2014, temos: Itajubá, Andrelândia, São Lourenço, Varginha, Barbacena, Diamantina, Conselheiro Lafaiete, Poços de Caldas, Juiz de Fora, Lavras.

Para as regiões com os maiores índices de analfabetismo em 2007, Nanuque, Salinas, Almenara correspondem respectivamente aos três primeiros colocados. Seguidos por: Pirapora, Conceição do Mato Dentro, Januária, Araçuaí, Peçanha, Mantena, Pedra Azul. Ao verificar os maiores índices de analfabetismo de 2014, é possível perceber que os três primeiros colocados se alteraram completamente Ituiutaba, Grão Mogol, Peçanha - nesta ordem -, entretanto, ainda compõem o grupo das dez microrregiões com maiores índices de analfabetismo do Estado mineiro, disponível a seguir: Nanuque, Salinas, Janaúba, Almenara, Aimorés, Teófilo Otoni, Ubá.

Em análise, é possível afirmar que as regiões que apresentam os menores índices de analfabetismo estão concentradas principalmente no Sul de Minas (Alfenas, Andrelândia, Itajubá, Poços de Caldas, São Lourenço e Varginha), na mesorregião dos Campos das Vertentes (Barbacena, Lavras e São João Del Rei) - que merecem destaque ainda maior por demonstrar que todas às suas microrregiões componham os menores índices de analfabetismo - e ainda, a região Metropolitana de $\mathrm{BH}$ (BH, Conselheiro Lafaiete e Sete Lagoas), áreas que estão dentro do polo mais desenvolvido do país. Enquanto que o Norte de Minas (Januária, Janaúba, Pirapora, Grão Mogol e Salinas), Jequitinhonha (Almenara, Araçuaí, Pedra Azul), Vale do Mucuri (Nanuque e Teófilo-Otoni), e Vale do Rio Doce (Peçanha, Mantena, Aimorés) são as áreas que concentram o maior gral de analfabetos do Estado. 


\subsubsection{Nível de Pobreza}

Figura 5: Nível de Pobreza em Minas Gerais 2007 e 2014

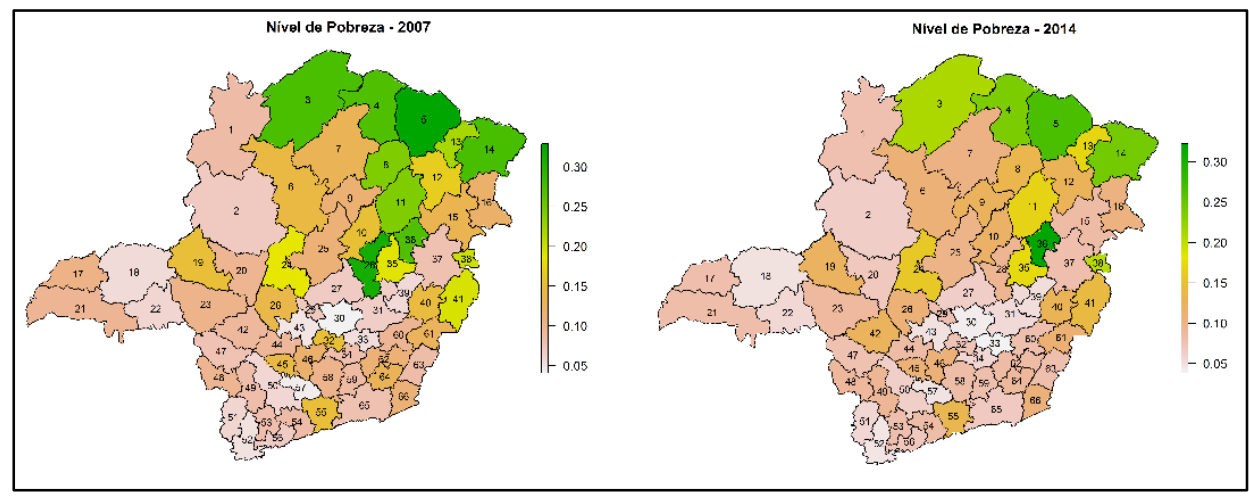

Fonte: Elaboração própria.

Esta variável normalmente representa deseconomias de urbanização, especialmente pelo fato do nível de pobreza ser sinônimo de altos custos sociais. Mas, sob olhar positivo, pode ser um fator atrativo para as atividades intensivas em trabalho, uma vez que equivale a um mercado de trabalho de baixo custo. É válido acentuar que a variável pobreza muitas vezes traduz o baixo poder aquisitivo da população (BETARELLI; SIMÕES, 2011).

A fórmula que compõe a variável - pessoal ocupado que recebe menos de um salário mínimo / pessoal ocupado urbano - indica que, determinada região, ao apresentar um índice de pobreza maior terá um grau maior de pessoas ocupadas urbanas recebendo menos de um salário mínimo. Sendo assim, por menores índices de nível de pobreza em 2007 apresenta-se: Belo Horizonte, Lavras, Divinópolis, Pouso Alegre, Ouro Preto, Uberlândia, Ipatinga, Varginha, Poços de Caldas, Uberaba. Entre os menores índices de nível de pobreza de 2014, estão: Ouro Preto, Belo Horizonte, Pouso Alegre, Lavras, Divinópolis, Uberlândia, Ipatinga, Itabira, Uberaba, Conselheiro Lafaiete.

Ao contrário, é possível observar quais são as microrregiões que apresentam os maiores índices de nível de pobreza (2007): Salinas, Conceição do Mato Dentro, Almenara, Januária, Janaúba, Peçanha, Capelinha, Grão Mogol, Pedra Azul, Mantena; e os maiores índices de nível de pobreza (2014): Peçanha, Salinas, Almenara, Janaúba, Januária, Mantena, Guanhães, Pedra Azul, Capelinha, Três Marias.

Diante as desigualdades, Vieira (2006) propõe que o sistema econômico-social de Minas Gerais apresenta muitas das características de subdesenvolvimento. A dramaticidade da pobreza no Norte de Minas (Januária, Janaúba, Salinas, Grão Mogol) e Jequitinhonha (Capelinha, Pedra Azul, Almenara) é mais bem entendida quando se verifica a participação pouco expressiva na geração do PIB dessas mesorregiões, quando se compara a média estadual (PDMI, 2003). De acordo com o Documento o nível de pobreza representaria ainda a persistência de dificuldades nas finanças públicas, de juros elevados e das baixas taxas de crescimento econômico, de altas taxas desemprego, e principalmente das desigualdades sociais que podem compor qualquer região.

\subsubsection{Massa Salarial da Indústria de Transformação}

Figura 6: Massa Salarial da Indústria de Transformação em Minas Gerais 2007 e 2014 


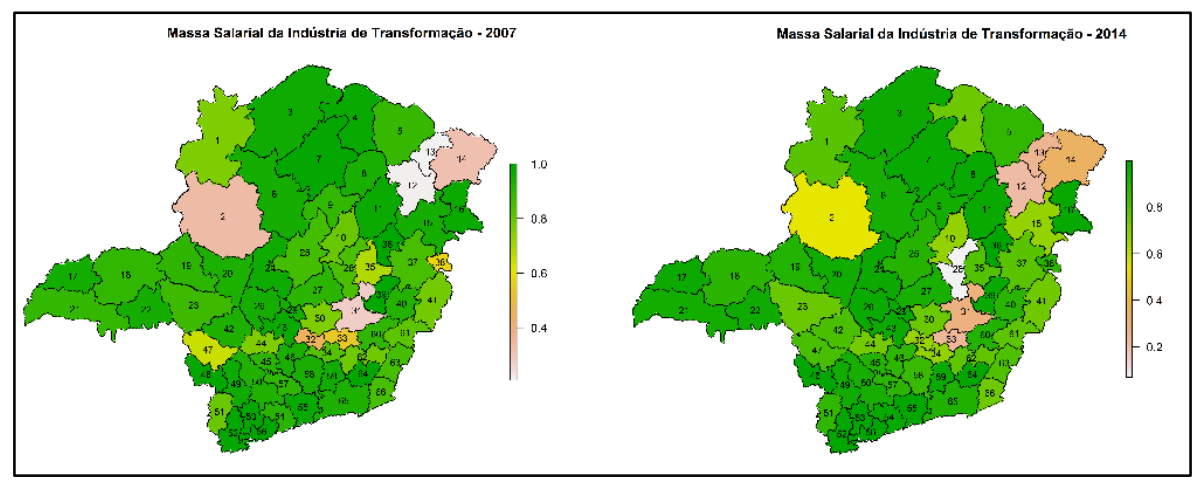

Fonte: Elaboração própria.

Tem-se o intuito de captar o peso relativo das atividades industriais das microrregiões analisadas, refletindo numa concentração relativa das áreas de mercado e os efeitos de encadeamentos oriundos de tais indústrias. Posto isto, tal variável denota um fator aglomerativo subjacente às economias de urbanização (BETARELLI; SIMÕES, 2011). Neste sentido os índices apresentados, indicam o quanto da massa salarial da indústria total de determinada microrregião advém da indústria de transformação.

Os menores índices de massa salarial da indústria de transformação (2007) são encontrados nas seguintes microrregiões: Pedra Azul, Araçuaí, Itabira, Almenara, Paracatu, Itaguara, Ouro Preto, Mantena, Passos, Guanhães. Em 2014, configura-se: Conceição do Mato Dentro, Araçuaí, Ouro Preto, Pedra Azul, Itabira, Almenara, Paracatu, Itaguara, Teófilo Otoni, Diamantina. Para os maiores índices de massa salarial da indústria de transformação de 2007, tem-se: Peçanha, Itajubá, Montes Claros, Ipatinga, Pouso Alegre, São Sebastião do Paraiso, Santa Rita do Sapucaí, Ubá, Andrelândia, Janaúba. Em 2014, os índices refletem o seguinte panorama: Peçanha, Itajubá, Santa Rita do Sapucaí, Ubá, Pouso Alegre, Andrelândia, São Sebastiao do Paraiso, Nanuque, Ipatinga, Montes Claros.

Cabe aqui, focar especialmente na microrregião de Conceição do Mato Dentro, que em 2007, dentre a massa salarial da industrial total (tratados em porcentagem), 84,6\% - relativamente alta - era proveniente da indústria de transformação. Em 2009 esse percentual aumenta para 85,7\% e cai bruscamente a partir de 2010 (26,8\%) e nos anos seguintes, 2011 (16\%), 2012 (9,4\%), 2013 (10,6) até alcançar o menor valor em 2014 (6,8\%). Segundo o Relatório final do Projeto Internacional de Pesquisa Cidades e Alteridades (2014), a mudança é explicada pela implantação do projeto Minas-Rio (de mineração) e instalação da mineradora sul-africana Anglo American que alteraram consideravelmente as esferas naturais, habitacionais, de saúde e segurança, e econômica da microrregião.

\subsubsection{Mercado}

Figura 7: Índice de Mercado em Minas Gerais 2007 e 2014

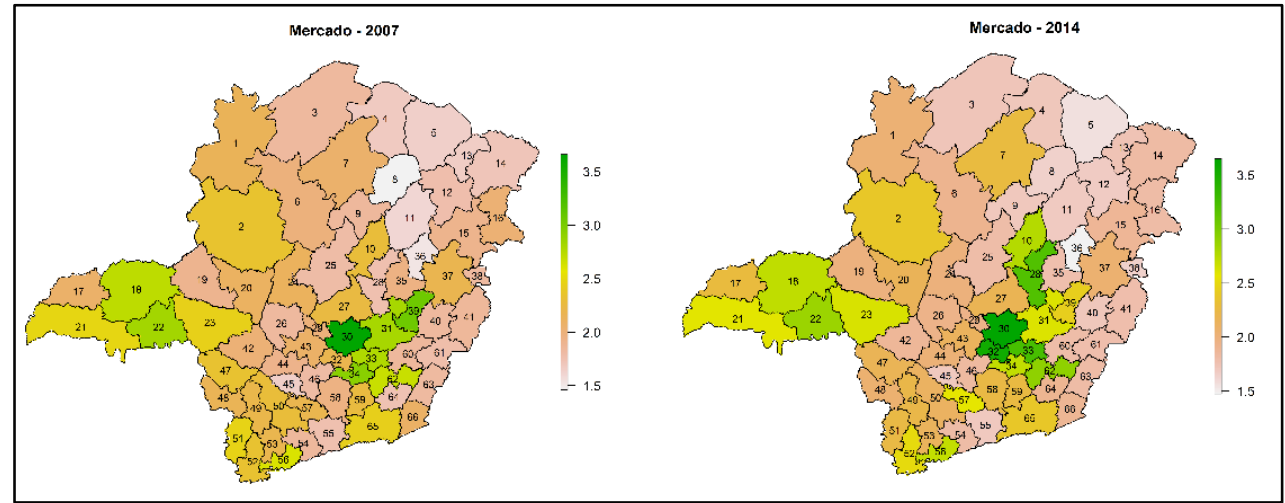

Fonte: Elaboração própria.

O propósito desta variável é tentar captar o poder de compra do mercado local (fator aglomerativo) que também pode ser tratada como custo da força de trabalho urbana (BETARELLI; SIMÕES, 2011). Torna-se fundamental esclarecer que neste trabalho a variável foi considerada somente 
como um fator aglomerativo de urbanização. Cabe dizer, ainda, que quanto maior for o índice total apresentado, maior é o poder de compra da população urbana daquela microrregião.

Em 2007, os menores índices de mercado concentram em: Grão Mogol, Peçanha, Capelinha, Salinas, Campo Belo, Pedra Azul, Janaúba, Almenara, Ubá, Conceição do Mato Dentro. Para 2014, temse o seguinte cenário: Peçanha, Salinas, Mantena, Grão Mogol, Araçuaí, Capelinha, Campo Belo, Andrelândia, Bocaiuva, Janaúba. Novamente, o destaque está em áreas conhecidas pelo baixo desenvolvimento o Norte de Minas (Grão Mogol, Salinas, Janaúba e Bocaiúva) e Jequitinhonha (Capelinha, Pedra Azul, Almenara e Araçuaí).

No que se refere aos maiores índices de mercado em 2007, dita-se: Belo Horizonte, Ipatinga, Conselheiro Lafaiete, Uberaba, Itabira, Ouro Preto, Uberlândia, Viçosa, Itajubá, Frutal. E para 2014 temos: Belo Horizonte, Itaguara, Ouro Preto, Conceição do Mato Dentro, Viçosa, Uberaba, Diamantina, Uberlândia, Conselheiro Lafaiete, Itajubá. Aqui, eleva-se as regiões Metropolitana de BH (BH, Itaguara, Itabira, Ouro Preto, Conselheiro Lafaiete e Conceição do Mato Dentro) e o Triângulo Mineiro (Uberlândia, Uberaba e Frutal) que apresentam os melhores índices - do ponto de vista do fator aglomerativo e poder de compra da população.

\subsubsection{Força de Trabalho Especializado}

Figura 8: Força de Trabalho Especializado em Minas Gerais 2007 e 2014

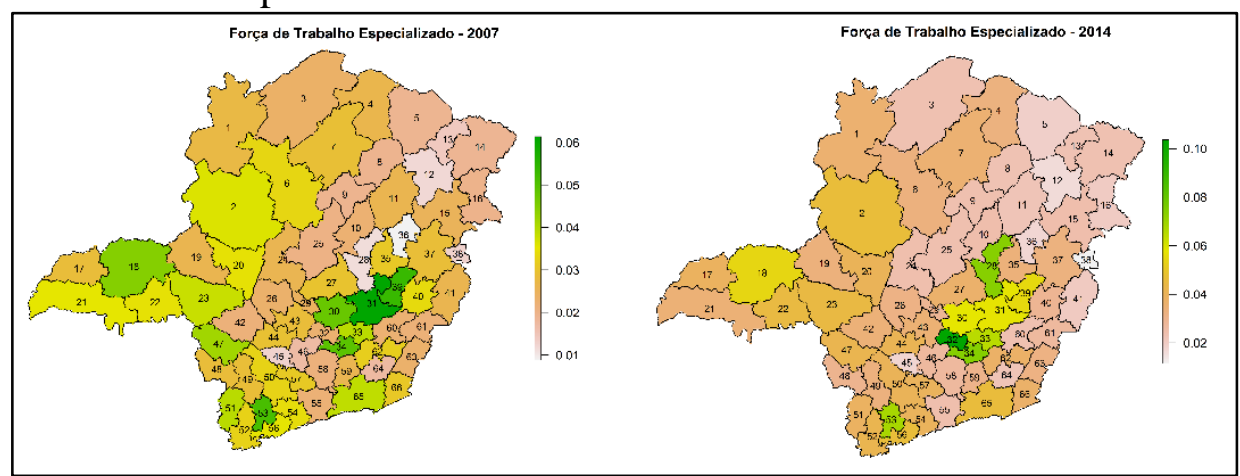

Fonte: Elaboração própria.

Pode ser definido pela obtenção do nível de qualificação da força de trabalho, o que representa uma vantagem potencial de uma região, ou seja, economias de urbanização (BETARELLI; SIMÕES, 2011). Quando focados na fórmula, por se tratar da divisão da população ocupada especializada (profissionais que demandam especialização de acordo com a RAIS ${ }^{6}$ ) pela população ocupada urbana, os índices tendem a se aproximar de zero (0). Porém, manifesta-se que os maiores índices de trabalho especializado estão nas microrregiões que apresentam maior nível de qualificação dentre os subgrupos analisados.

Como pode ser visto, existe uma menor concentração de trabalho especializado, em 2007, nas seguintes microrregiões: Peçanha, Conceição do Mato Dentro, Araçuaí, Campo Belo, Mantena, Pedra Azul, Oliveira, Ubá, Almenara, Salinas. Em 2014, o quadro se apresenta assim: Mantena, Araçuaí, Peçanha, Campo Belo, Salinas, Nanuque, Aimorés, Ubá, Capelinha, Grão Mogol. Em contrapartida, a seguir são apresentados os maiores índices de força de trabalho especializado em 2007: Itabira, Ipatinga, Santa Rita do Sapucaí, Conselheiro Lafaiete, Belo Horizonte, Uberlândia, Passos, Ouro Preto, Poços de Caldas, Juiz de Fora. E para 2014: Itaguara, Conselheiro Lafaiete, Conceição do Mato Dentro, Santa Rita do Sapucaí, Ouro Preto, Belo Horizonte, Itabira, Ipatinga, Uberlândia, Itajubá.

\footnotetext{
${ }^{6}$ Profissionais que demandam especialização: Profissionais da Biotecnologia e Metrologia; Profissionais da Eletromecânica; Pesquisadores; Profissionais da Informática; Físicos, Químicos e Afins; Engenheiros, Arquitetos e Afins; Biólogos e Afins; Agrônomos e Afins; Profissionais de Organização e Administração de Empresas e Afins; Profissionais de Relações Públicas, Publicidade, Marketing e Comercialização; Técnicos Mecatrônicos e Eletromecânicos; Técnicos em Laboratório; Técnico em Ciências Físicas e Químicas; Técnicos em Construção Civil, de Edificações e Obras de Infraestrutura; Técnicos em Eletroeletrônica e Fotônica; Técnicos em Metalomecânica; Técnicos em Mineralogia e Geologia; Técnicos em Informática; Desenhistas Técnicos e Modelistas; Outros Técnicos de Nível Médio das Ciências Físicas, Químicas, Engenharia e Afins; Técnicos em Biologia; Técnicos da Produção Agropecuária; Técnicos da Ciência da Saúde Animal; Técnicos de Bioquímica e da Biotecnologia.
} 
Em análise, Conceição do Mato Dentro, chama atenção, pelo fato de que em 2007 apresentava-se com a segunda microrregião com menor índice de trabalho especializado, que em 2014, passa a ser a terceira região com maior especialização da força de trabalho, provavelmente devido ao grandioso projeto minerador que incorporou-se na região, mais profundamente a partir de 2008. Destaca-se ainda que os menores índices estão concentrados nas mesorregiões do Jequitinhonha (Araçuaí, Almenara, Capelinha e Pedra Azul) e Vale do Rido Doce (Peçanha, Mantena, Aimorés) e Norte de Minas (Salinas e Grão Mogol). Enquanto que os maiores índices de especialização são encontrados principalmente nas regiões Metropolitana de BH (Conceição do Mato Dentro, Itabira, Conselheiro Lafaiete, BH, Ouro Preto e Itaguara), e Sul de Minas (Santa Rita do Sapucaí, Poços de Caldas e Itajubá); e ainda na microrregião de Uberlândia (Triângulo Mineiro) que apareceu tanto em 2007 quanto 2014.

\subsubsection{Oferta de Serviços Produtivos}

Figura 9: Oferta de Serviços Produtivos em Minas Gerais 2007 e 2014

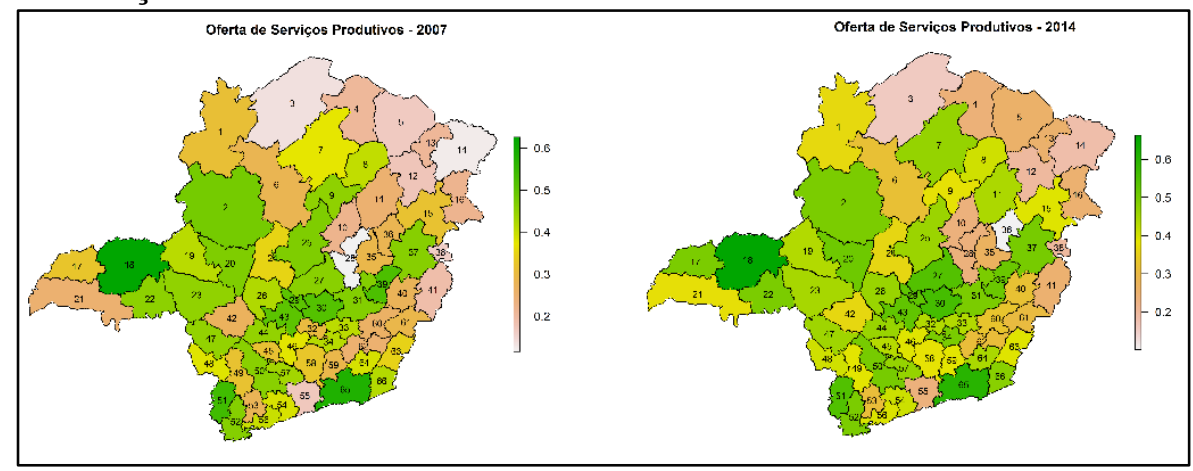

Fonte: Elaboração própria.

Esta variável diz respeito ao conceito de economias de urbanização, de modo que, indica o nível relativo de oferta de serviços dinâmicos (BETARELLI; SIMÕES, 2011). Vale recordar que economias de urbanização são economias de escala, externas às firmas e também à indústria (FOCHEZATTO; VALENTINI, 2010). Nesta situação em análise, temos que quanto maior o índice, maior será a oferta de serviços especializados na determinada microrregião, ou seja, uma relação diretamente proporcional entre os componentes da fórmula.

Para 2007, os menores índices de oferta de serviços produtivos estão representados, respectivamente em: Conceição do Mato Dentro, Almenara, Januária, Mantena, Salinas, Andrelândia, Araçuaí, Aimorés, Janaúba, Pedra Azul. Em 2014, tem-se o panorama a seguir: Peçanha, Januária, Almenara, Mantena, Araçuaí, Conceição do Mato Dentro, Diamantina, Andrelândia, Janaúba, Aimorés. No que se refere aos maiores índices de oferta de serviços produtivos (2007), os resultados demonstram: Uberlândia, Juiz de Fora, Poços de Caldas, Ipatinga, Belo Horizonte, Divinópolis, Para de Minas, Paracatu, Curvelo, Patos de Minas. Bem como, para os maiores índices de oferta de serviços produtivos (2014), temos: Uberlândia, Juiz de Fora, Belo Horizonte, Poços de Caldas, Sete Lagoas, Para de Minas, Divinópolis, Ipatinga, Patos de Minas, Governador Valadares.

É notório que os valores mais baixos para os índices de oferta de serviços produtivos estão em mesorregiões menos prósperas, tais como: o Jequitinhonha (Diamantina, Almenara, Araçuaí e Pedra Azul), Norte de Minas (Januária, Janaúba e Salinas) e Vale do Rio Doce (Peçanha, Mantena e Aimorés). Ao passo que os maiores índices de oferta de serviços produtivos são exprimidos pelas microrregiões mais populosas - quiçá desenvolvidas - dentre as suas mesorregiões.

\subsubsection{Economia de Escala}

Figura 10: Economia de Escala em Minas Gerais 2007 e 2014 


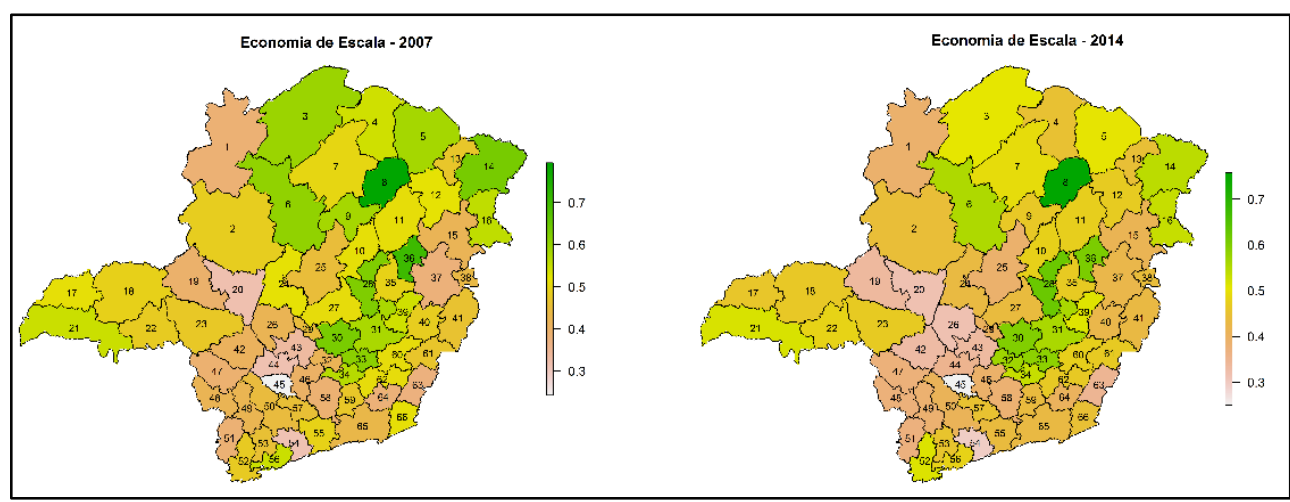

Fonte: Elaboração própria.

Esta variável diz respeito às economias de escala, que normalmente decorrem do aumento das quantidades produzidas, da melhoria da eficiência produtiva, da melhor organização da produção no nível da empresa (SOUZA, 2009), mas que propriamente neste estudo, apresentar-se-á como função do tamanho relativo das empresas. Trata-se, portanto, do interesse de conhecer os índices microrregionais do pessoal ocupado urbano que estão empregados em indústrias com mais de 100 funcionários.

Deste modo, temos, em relação aos menores índices de economia de escala (2007): Campo Belo, São Lourenco, Formiga, Patos de Minas, Divinópolis, Muriaé, Governador Valadares, Ubá, Unaí, Poços de Caldas. Em 2014, revela-se: Campo Belo, São Lourenco, Patos de Minas, Bom Despacho, Piumhi, Divinópolis, Patrocínio, Muriaé, Formiga, Poços de Caldas. Na contramão, são apresentados os maiores índices de economia de escala de 2007: Grão Mogol, Peçanha, Almenara, Belo Horizonte, Conceição do Mato Dentro, Ouro Preto, Pirapora, Januária, Salinas, Bocaiuva; e de 2014: Grão Mogol, Conceição do Mato Dentro, Peçanha, Belo Horizonte, Ouro Preto, Itaguara, Itabira, Pirapora, Almenara, Nanuque.

Neste ensejo, cabe acentuar que, as regiões que mostram índices menores de economia de escala sugerem uma menor dependência da grande indústria, geralmente configuradas por aglomerações de economia, ou seja, economias mais dinâmicas e diversificadas. De modo contrário, as microrregiões que apresentam os maiores índices de economia de escala são propensas a devotar forte dependência da grande indústria ali instalada, principalmente ao que se refere a disponibilidade de emprego, e consequentemente a renda da população.

\subsubsection{Quociente Locacional (QL)}

O QL é uma medida de especialização, utilizada para verificar a concentração de atividades econômicas existentes em uma região. Calcula-se a concentração de um grupo de empresas de determinado setor industrial em um determinado município, por exemplo, em relação ao total de empresas existentes em um estado, como é o caso deste estudo. Com esses indicadores, é possível identificar os níveis de especialização, identificar as atividades afins e potenciais cadeias produtivas existentes nas áreas investigadas (FEGER; ETGES; ROSSETTO, 2010). Betarelli e Simões (2011) argumentam que o QL tem por finalidade capturar as “economias de localização”, uma vez que o quociente locacional é uma medida que compara a participação percentual de uma região com a participação percentual no total de emprego estadual.

Para realização desta pesquisa, foram portanto utilizados os três grupos da indústria de transformação utilizados no trabalho de Betarelli e Simões (2011), que executaram pesquisa semelhante para o Estado de São Paulo. Haja vista, os grupos indústrias são definidos a seguir:

a) QLWEB (Indústria Weberiana): as indústrias são intensivas em capital e orientadas a se localizar próximo da sua matéria-prima. São elas: fabricação de celulose papel e produtos de papel; impressão e reprodução de gravações; fabricação de produtos de minerais não metálicos; metalurgia; fabricação de produtos de metal exceto máquinas e equipamentos.

b) QLDINAM (Indústrias Dinâmicas): a maioria dos setores é atraída para os centros consumidores com ampla oferta de serviços produtivos e demandam força de trabalho qualificada. São elas: fabricação de coque de produtos derivados do petróleo e de 
biocombustíveis; fabricação de produtos químicos; fabricação de produtos farmoquímicos e farmacêuticos; fabricação de equipamentos de informática produtos eletrônicos e ópticos; fabricação de máquinas aparelhos e materiais elétricos; fabricação de máquinas e equipamentos; fabricação de veículos automotores reboques e carrocerias; fabricação de outros equipamentos de transporte exceto veículos automotores; manutenção reparação e instalação de máquinas e equipamentos.

c) QLTRAD (Indústrias Tradicionais): os setores são intensivos em trabalho, inclusive demandam baixa qualificação da força de trabalho, e são direcionados para locais com baixos salários. São elas: fabricação de produtos alimentícios; fabricação de bebidas; fabricação de produtos do fumo; fabricação de produtos têxteis; confecção de artigos do vestuário e acessórios; preparação de couros e fabricação de artefatos de couro artigos para viagem e calçados; fabricação de produtos de madeira; fabricação de produtos de borracha e de material plástico; fabricação de móveis; fabricação de produtos diversos.

Finalmente, elucida-se aqui que às análises referentes aos quocientes locacionais serão apresentadas no segundo momento deste artigo, em que busca-se uma maior compreensão entre todas as variáveis descritas, além de buscar uma correlação, tendo a finalidade de detalhar com mais clareza os aspectos da estrutura produtiva de Minas Gerais para os anos de 2007 e 2014.

\subsection{CORRELACIONANDO OS DADOS}

Neste segundo momento as variáveis passam a se correlacionarem, positiva ou negativamente com os três grupos da indústria de transformação: QLWEB, QLDINAM, e QLTRAD.

Ao referirmos ao grupo QLWEB, foi possível notar uma concentração da fabricação de celulose papel e produtos de papel nas microrregiões de Cataguases $(12,6 / 9,74)$, Guanhães $(9,16 / 12,37)$ e São Lourenço $(6,56 / 4,97)$ com algumas alterações na ordem de 2007 para 2014, mas mantendo basicamente as mesmas microrregiões em destaque. $\mathrm{Na}$ atividade impressão e reprodução de gravações sobressaem as microrregiões Nanuque (8,89), Diamantina $(7,03)$, Teófilo Otoni $(5,31)$, Viçosa $(4,42)$, Muriaé $(3,03)$, Juiz de Fora $(2,97)$ em 2007; e Teófilo Otoni $(3,64)$, Juiz de Fora $(2,98)$, Nanuque $(2,83)$, Viçosa $(2,58)$, Diamantina $(2,53)$ e Frutal $(2,44)$ em 2014. Nota-se, nas duas atividades, que algumas das microrregiões apresentadas (Cataguases, Juiz de Fora, Viçosa e Muriaé) fazem parte da Zona da Mata, o que ajudaria a caracterizar a mesorregião. Entre os aspectos em destaque para esses tipos de indústrias podemos considerar o baixo índice de economia de escala, demonstrando que empresas de pequeno e médio porte são suficientes para compor esse tipo de serviço. Guanhães, uma das microrregiões que opera esse tipo de fabricação apresentou altos níveis de pobreza o que insinuaria um mercado de trabalho de baixo custo.

Para a fabricação de produtos de minerais não metálicos o Grão Mogol $(4,22)$, Araçuaí $(3,98)$, Patrocínio (3,85), Salinas $(3,78)$, Januária $(3,75)$, Capelinha $(3,59)$ e Janaúba $(3,46)$ em 2007; Grão Mogol (3,22), Araçuaí (3,14), Salinas (3,04), Pedra Azul (2,99) e Januária (2,98) em 2014 são as áreas realçadas; em metalurgia Bocaíuva $(2,36)$, Pirapora $(2,30)$, Conselheiro Lafaiete $(2,18)$, Itaguara $(1,97)$ e Pará de Minas (1,57) para 2007; e Itaguara (2,83), Pirapora (2,73), Bocaiúva $(2,59)$ e Conselheiro Lafaiete $(2,42)$ para 2014. Temos, nas respectivas atividades, microrregiões do Norte de Minas e a região Metropolitana de $\mathrm{BH}$ em destaque. A respeito do primeiro tipo de indústria, cabe determinar que a mesma se relaciona com regiões de alto índices de analfabetismo e nível de pobreza, e baixa concentração do nível de trabalho especializado. Enquanto isso, a metalurgia se relaciona bem com regiões que apresentam índices maiores de grau de industrialização. Para os dois casos é mais comum a economia de escala e uma possível dependência dessas microrregiões para com suas indústrias.

A fabricação de produtos de metal exceto máquinas e equipamentos se mostrou concentrada nas microrregiões: Itajubá (3,19), Pouso Alegre $(2,086)$ e Varginha $(2,081)$ em 2007; e Itajubá $(3,13)$, Viçosa $(2,14)$ e Varginha $(1,96)$ em 2014) - Itajubá inclusive garantiu o maior índice locacional tanto para 2007 como para 2014. O Triângulo Mineiro (tendo Uberlândia, Patos de Minas e Uberaba) e a Zona da Mata (Viçosa e Ponte Nova) também foram relevantes, mas foi a microrregião de Paracatu $(1,23 / 1,94)$ (Noroeste) que mostrou o maior desenvolvimento, passando de $13^{\mathrm{a}}$ para $4^{\mathrm{a}}$ colocada entre os anos estudados. O que chama atenção para esta indústria é sua localização em áreas com baixo índice de 
analfabetismo. As microrregiões também apresentaram um alto fator aglomerativo, devido principalmente aos altos índices de mercado e de especialização do trabalho. Vale ressaltar, entretanto, que as microrregiões de Itajubá e Pouso Alegre demonstraram altos índices de massa salaria da indústria de transformação, que instiga certa dependência da indústria em análise.

Para o próximo grupo, QLDINAM, ao apontar para a fabricação de coque de produtos derivados do petróleo e de biocombustíveis, apesar da microrregião de Nanuque $(26,60 / 14,64)$ manter a primeira posição tanto para 2007 como 2014, essa atividade demonstrou um acúmulo para a mesorregião do Triângulo Mineiro, sendo que Ituiutaba (1,21/13,79), Frutal $(4,48 / 11,39)$ e Araxá $(15,61 / 11,07$ mesmo mostrando uma baixa no seu índice) se estabeleceram entre os principais fabricantes - que são seis (Nanuque, Ituiutaba, Três Marias, Paracatu, Frutal e Araxá). Na fabricação de produtos químicos, nota-se uma maior movimentação, sendo que em 2007 se destacavam as microrregiões de Bocaíuva (7,75), Grão Mogol $(7,75)$ e Salinhas $(7,64)$ (Norte de Minas), mas se espalharam pelas demais microrregiões em 2014, Salinas $(7,76)$ (Norte de Minas), Pium-í $(7,54)$ e Formiga $(6,45)$ (Oeste de Minas), Manhuaçu $(5,48)$ (Zona da Mata), Araçuaí $(5,33)$ e Pedra azul $(5,19)$ (Jequitinhonha), Teófilo Otoni $(4,73)$ (Mucuri) e Bom Despacho $(4,56)$ (Central). É possível estabelecer, diante das microrregiões verificadas, a baixa exigência de qualificação para esse tipo de atividade, devido aos altos índices de analfabetismo anteriormente encontrados.

Para a fabricação de produtos farmoquímicos e farmacêuticos, Diamantina $(11,26)$ que foi a primeira colocada em 2007 mostra valor zero para o mesmo índice em 2014. Montes Claros passa de segundo melhor índice em 2007 para a primeira posição em 2014 (10,37/13,50). Entretanto, é importante revelar que foi a Mesorregião Zona da Mata (nas microrregiões de Viçosa (8,21/4,96), Juiz de Fora $(3,84 / 4,75)$ e Muriaé $(3,00 / 1,21))$ que revelou um maior número de microrregiões envolvidas com esta atividade para os dois anos em análise. Aparentemente, essas atividades relacionam-se com microrregiões que apresentem menores graus de industrialização, isso porque permite menor dependência do setor, normalmente encontradas em regiões mais economicamente estabelecidas.

Ao analisar a fabricação de equipamentos de informática produtos eletrônicos e ópticos, as microrregiões de Santa Rita do Sapucaí $(7,61)$, Varginha $(2,86)$, Pouso Alegre $(1,87)$, Itajubá $(0,80)$ e São Sebastião do Paraíso $(0,76)$ (todas do Sul de Minas) dominavam esse tipo de indústria em 2007, juntamente com Sete Lagoas (1,03) e Belo Horizonte (0,78) (Metropolitana de BH). Para 2014, as microrregiões Sul Mineiras mantem-se praticamente estáveis e Bocaíuva $(8,56)$ e Montes Claros $(2,16)$ (Norte de Minas) apresentam um ascendente crescimento. Adiante, na fabricação de máquinas, aparelhos e materiais elétricos, a microrregião de Governador Valadares $(6,95 / 5,75)$ demonstrou o maior índice para 2007 e 2014. Contudo, o Sul de Minas - que apresentava quatro microrregiões (São Sebastião do Paraíso (4,48), Poços de Caldas (2,94), Varginha $(2,22)$ e Santa Rita do Sapucaí $(1,29)$ ) com altos indicadores para esta indústria em 2007, aumentou para seis microrregiões (São Sebastião do Paraíso $(3,82)$, Poços de Caldas $(2,47)$, Santa Rita do Sapucaí $(2,42)$, Varginha $(2,09)$, Itajubá $(1,43)$ e Alfenas $(1,40)$ ) em 2014 - entre dez que apresentaram os maiores índices de fabricação de máquinas e materiais elétricos. São estas, as microrregiões que basicamente demonstraram os maiores índices de força de trabalho especializado, com boa parte de sua massa salarial da indústria de transformação, e ainda, baixos níveis de analfabetismo.

Apontando para a fabricação de máquinas e equipamentos, observa-se um movimento de dispersão entre os anos de 2007 e 2014, como veremos a seguir: para o primeiro ano temos uma maior concentração nas microrregiões de São Lourenço $(6,37)$, Passos $(2,01)$ e São Sebastião do Paraíso $(1,69)$ (Sul de Minas) e Ituiutaba $(2,82)$, Patrocínio $(2,78)$ e Uberlândia $(2,23)$ (Triângulo); já no segundo ano analisado, tornam-se destaque as microrregiões de São Lourenço $(6,96)$ e São Sebastião do Paraíso $(3,11)$ (Sul de Minas) - nota-se a saída de Passos -, Diamantina $(6,82)$ e Capelinha $(3,99)$ (Jequitinhonha), Ubá $(4,40)$ e Cataguases $(3,97)$ (Zona da Mata), Caratinga $(3,67)$ e Ipatinga $(2,53)$ (Rio Doce), e Itaguara (2,55) (Metropolitana de $\mathrm{BH})$ - nota-se a saída por completo, entre os melhores índices, das microrregiões que fazem parte do Triângulo Mineiros, apresentadas para o ano de 2007.

Ao contrário da indústria anterior, a fabricação de veículos automotores reboques e carrocerias, mostra-se muito mais concentrada ao longo dos anos. Em 2007, a microrregião de Lavras (2,37) (Campo das Vertentes) apresentava o melhor índice da atividade, seguida de Ouro preto $(2,25)$, Pará de Minas 
$(1,83)$, Sete Lagoas $(1,76)$ e Belo Horizonte $(1,11)$ (Metropolitana de BH) e Itajubá $(1,99)$, Pouso Alegre $(1,26)$, Alfenas $(1,14)$ e Varginha $(0,92)$ (Sul de Minas). Em 2014, Lavras $(2,59)$ cai para a segunda posição, que é assumida por Conceição do Mato Dentro $(2,74)$ (Metropolitana de BH - região esta que ainda mantém Ouro preto $(2,14)$, Pará de Minas $(2,06)$, Sete Lagoas $(1,68)$ e Belo Horizonte $(1,28)$ entre os maiores indicadores). Destaca-se, as regiões Metropolitanas de $\mathrm{BH}$ como as mais características às economias de escala. Alega-se, por fim, que o Sul de Minas também mantém suas microrregiões, que ainda foram complementadas por Poços de Caldas.

A fabricação de outros equipamentos de transporte exceto veículos automotores, foi outra atividade a mostrar dispersão entre os anos em análise. Assim, temos que em 2007, Andrelândia (115,26), Passos $(23,92)$, São Lourenço $(3,03)$, Itajubá $(2,63)$ e Poços de Caldas $(1,56)$ (Sul de Minas) estavam entre os principais índices, sugerindo uma centralização. É ainda importante perceber que são microrregiões menos especializadas, e consequentemente, mais diversificadas. Em 2014, apesar da expressiva baixa no índice de Andrelândia $(7,30)$, Passos $(25,04)$ e Itajubá $(6,01)$ demonstram uma evolução em seus índices. Além disso, a atividade mostrou-se mais dispersa, agora entre as microrregiões de Caratinga (11,76) e Governador Valadares (3,71) (Rio Doce), Bom Despacho (8,34) (Central), Diamantina $(6,18)$ (Jequitinhonha), Sete Lagoas $(2,11)$ e Belo Horizonte $(0,87)$ (Metropolitana de BH), Divinópolis $(1,63)$ (Oeste) e Viçosa $(0,94)$ (Zona da Mata). A manutenção reparação e instalação de máquinas e equipamentos, também indica um processo de desagregação, principalmente a mesorregião Metropolitana de BH. Esta, em 2007, apresentava as microrregiões Conselheiro Lafaiete $(9,15)$, Itabira $(7,60)$ e Itaguara $(2,80)$ com os melhores índices da referida atividade, que ao longo dos anos foram perdendo espaço para outras microrregiões como, Januária $(9,43)$ e Pirapora $(9,06)$ (Norte de Minas), Curvelo $(7,54)$ (Central), Almenara $(7,07)$ (Jequitinhonha), Aimorés $(6,46)$ (Rio Doce), Unaí $(6,24)$ (Noroeste) e Andrelândia $(6,00)$ (Sul).

No terceiro, e último grupo, QLTRAD ao verificar a fabricação de produtos alimentícios, diferente do que podemos perceber nas indústrias do grupo QLDINAM - exclusivamente para a esta atividade -, nota-se que os índices são quase que igualitariamente distribuídos entre todas as regiões do Estado de Minas Gerais, e sem grandes mudanças para os anos analisados. Inclusive as microrregiões de Nanuque (2,63/2,50) (Mucuri), Ituiutaba (2,62/2,49) e Frutal (2,53/2,39) (Triângulo) foram respectivamente os três maiores indicadores tanto para 2007 como para 2014. O fato curioso, nesta análise, está voltado para o Grão Mogol, dado que foi a única microrregião que demonstrou valor zero ao índice nos dois respectivos anos. A alta capacidade de inserção desta atividade em diferentes microrregiões denota a baixa necessidade de qualificação da força de trabalho, de oferta de serviços produtivos e a uma completa variação da economia de escala.

Para a fabricação de bebidas, as microrregiões Salinas (7,97/9,31) e Januária (4,01/2,96) (Norte de Minas) e Ouro Preto (3,35/7,82), Conceição do Mato Dentro (3,53; em 2007) Sete Lagoas (4,15; em 2014) e Belo Horizonte (2,43/2,35) (Metropolitana de BH), São Lourenço $(3,86 / 3,62)$ (Sul) demonstram ter os melhores índices ao longo dos anos. Além destas, Uberlândia $(2,55 / 4,71)$ foi a única região do Triângulo a mostrar destaque em 2007 e 2014 no que se refere a indústria de bebidas. Entretanto, é válido sublinhar que esta atividade é expressivamente desenvolvida em várias microrregiões de Minas Gerais. Para Uberlândia $(11,14 / 14,47)$, chama-se atenção ainda a fabricação de produtos do fumo, que é praticamente toda concentrada nesta microrregião, mostrando índices extremamente altos quando comparados aos índices das poucas microrregiões que também participam desta atividade.

Ao referirmos a fabricação de produtos têxteis, Diamantina $(8,34 / 9,95)$ (Jequitinhonha) Pirapora (7,90/9,79), Montes Claros (6,04/4,18) (Norte), Curvelo $(6,45 / 8,09)$ (Central), Sete Lagoas $(4,48 / 4,27)$, Ouro Preto $(4,39 / 2,18)$, Pará de Minas $(2,94 / 2,23)$ e Itabira $(2,93 / 3,17)$ (Metropolitana de BH) mantém os primeiros lugares para 2007 e 2014. É válido considerar que algumas das microrregiões em destaque tem demostrado expansão na fabricação destes produtos têxteis, e que esta é uma atividade comumente realizada em diferentes regiões, apesar de haver uma suave concentração na mesorregião Metropolitana de BH. Ao mesmo tempo, a confecção de artigos do vestuário e acessórios, que em 2007 mostrou-se espalhada em microrregiões como Mantena $(4,49)$ (Rio Doce), Formiga $(3,40)$ e Campo Belo $(3,30)$ (Oeste de Minas), Muriaé $(3,13)$ e Juiz de Fora $(2,68)$ (Zona da Mata), Santa Rita do Sapucaí $(2,46)$ e Poços de Caldas (1,97) (Sul de Minas), Lavras (1,72) (Campo das Vertentes) demonstrou estar mais 
centralizada no ano de 2014, sobretudo em Mantena (5,04) e Peçanha $(2,25)$ (Rio Doce), Muriaé $(3,12)$ e Juiz de Fora $(2,95)$ (Zona da Mata), Campo Belo $(3,68)$ e Formiga $(2,69)$ (Oeste de Minas), Santa Rita do Sapucaí $(2,41)$ e Poços de Caldas $(2,28)$ (Sul de Minas).

Ao averiguar à preparação de couros e fabricação de artefatos de couro artigos para viagem $e$ calçados, entende-se que são atividades concentradas basicamente em Divinópolis $(5,22 / 5,49)$, Oliveira (1,99/1,04), Pium-í (1,39/1,36) e Formiga (1,85 em 2014) (Oeste), São João Del Rei $(4,87 / 4,31)$ (Campo das Vertentes), Andrelândia (3,18 em 2014), São Sebastião do Paraíso $(1,80 / 1,95)$ e Passos $(1,57 / 1,63)$ (Sul), e Bom Despacho (2,21/1,29) (Central) tanto em 2007 como 2014. Caracteriza-se, portanto, tal atividade pela baixa necessidade de se instalar em regiões com altos níveis de oferta de serviços produtivos, e ainda, fica evidente os baixos índices de economia de escala, em que, indústrias de pequeno e médio porte podem garantir o bom andamento desse negócio.

Para a fabricação de produtos de madeira, praticamente todas as microrregiões possuem indústrias associadas a esses produtos - à exceção de Januária. Porém, o destaque nesta atividade está para o Grão Mogol $(28,98)$ (Norte de Minas) que em 2007 já mostrava o dobro da produção do segundo colocado Araxá $(14,20)$ (Triângulo). Em 2014, o Grão Mogol $(38,46)$ mostrou uma proporção muito mais elevada em comparação as outras microrregiões: Capelinha $(11,92)$ (Jequitinhonha) - a segunda colocada daquele ano - já demonstrava um índice bem abaixo do Grão Mogol e a microrregião de Araxá $(9,16)$ cai para terceira posição. Nota-se que os índices apontam para uma centralização da fabricação de produtos de madeira em 2014, que já ocorria em 2007, porém, em escala menor. Ao referir a fabricação de móveis, percebe-se que é uma indústria de extrema diversificação dentro do Estado de Minas Gerais. Apesar de pequenas diferenças nos índices desta atividade, Ubá $(6,59 / 6,18)$ (Zona da Mata), Itaguara $(6,52 / 4,62)$ (Metropolitana de BH), Três Marias (3,51/2,62) (Central), Andrelândia (2,37/2,13) (Sul de Minas), merecem ser destacadas. Evidencia-se, contudo, os baixos atributos aglomerativos das atividades mencionadas.

Por último, a fabricação de produtos de borracha e de material plástico, se mostrava mais dispersa no ano de 2007, com indústrias em várias microrregiões, tais como Varginha $(4,43)$ (Sul), Oliveira $(3,13)$ (Oeste), Belo Horizonte $(2,46)$ (Metropolitana de BH), Governador Valadares $(1,60)$ (Rio Doce), Almenara $(1,36)$ (Jequitinhonha) e Ponte Nova $(1,14)$ (Zona da Mata). O ano de 2014, entretanto, acentua que a atividade tem se concentrado especialmente nas microrregiões do Sul de Minas (Varginha $(4,51)$, São Lourenço $(2,48)$, Pouso Alegre $(2,04)$ e Poços de Caldas $(1,27))$, Metropolitana de BH (Ouro Preto $(2,97)$ e Belo Horizonte $(2,47))$ e Oeste de Minas (Oliveira $(3,81)$ e Formiga $(1,35))$. Neste mesmo caminho, a fabricação de produtos diversos, mostra-se em processo cumulativo - numa menor escala em 2007, e maior em 2014 - principalmente nas seguintes microrregiões: Pouso Alegre (4,75 em 2007), Itajubá (2,88/4,29), São Sebastião do Paraíso (2,68/2,87), São Lourenço (2,29 em 2007) e Santa Rita do Sapucaí (4,07 em 2014) (Sul de Minas), Teófilo Otoni (4,29/4,12) (Vale do Mucuri), e Itaguara (2,96 em 2007), Belo Horizonte (1,62/ 2,10) e Conselheiro Lafaiete (2,27 em 2014) (Metropolitana de BH).

\section{CONSIDERAÇÕES FINAIS}

Este trabalho pretendeu analisar a estrutura produtiva de Minas Gerais, a partir dos fatores característicos das 66 microrregiões que compõe o Estado para os anos de 2007 e 2014 . Foram propostas doze variáveis que ajudam a explicar a dinâmica econômica e industrial das regiões, por meio da estrutura de emprego e principais fatores locacionais de urbanização, sendo elas: o coeficiente de especialização, grau de industrialização, analfabetismo, nível de pobreza, massa salarial da indústria de transformação, mercado, força de trabalho especializado, oferta de serviços produtivos e economia de escala; que ao serem conciliadas com medidas de especialização (quociente locacional - QL) - através dos três grupos industriais QLWEB, QLDINAM, QLTRAD - atestam os propósitos da pesquisa.

Portanto, especificamente da Indústria Weberiana (QLWEB) que geralmente são intensivas em capital e orientadas a se localizar próximo da sua matéria-prima, foi possível identificar uma maior integração às microrregiões de Juiz de Fora, Cataguases, Ponte Nova, Ubá, Viçosa e Muriaé (Zona da Mata) e Januária, Janaúba, Grão Mogol, Bocaiúva, Pirapora e Salinas (Norte de Minas). Com exceção de Juiz de Fora, considerada o principal polo industrial da sua mesorregião, é possível destacar o alto coeficiente de especialização apresentado pelas demais regiões, confirmando a estrutura retraída e menos 
diversificada expressa por este índice. Os índices de analfabetismo e nível de pobreza também se mostraram significativos dentro destas microrregiões, o que neste caso, pode representar uma fonte de atração para setores não demandantes de qualificação e um mercado de trabalho de baixo custo, respectivamente. Ressalta-se, exclusivamente para a fabricação de produtos de metal exceto máquinas $e$ equipamentos, uma alta concentração desta atividade nas microrregiões da Metropolitana de BH (Conselheiro Lafaiete, Itaguara e Pará de Minas) e Sul de Minas (Itajubá, Pouso Alegre e Varginha) que se caracterizam de características bem distintas daquelas destacadas neste parágrafo.

Para as Indústrias Dinâmicas (QLDINAM), ou seja, a maioria dos setores que são atraídas por centros consumidores com ampla oferta de serviços produtivos e demandam força de trabalho qualificada, é notória a centralidade das microrregiões que compõe o Sul de Minas (São Sebastião do Paraíso, Pouso Alegre, Varginha, Alfenas, Andrelândia, Poços de Caldas, Santa Rita do Sapucaí, Itajubá, São Lourenço e Passos) e a região Metropolitana de BH (Sete Lagoas, Conceição do Mato Dentro, Pará de Minas, Belo Horizonte, Itabira, Itaguara, Ouro Preto e Conselheiro Lafaiete). É plausível afirmar também o bom desempenho das microrregiões que compõem o Campo das Vertentes (notadamente, Lavras e São João Del Rei) e as áreas que se tornaram polos em suas mesorregiões, como Uberlândia (Triângulo Mineiro) e Montes Claros (Norte de Minas) - regiões polarizadas. Prevalece, deste modo, as regiões mais alfabetizadas, com oferta de serviços produtivos e força de trabalho mais qualificada, o mercado mais diversificado e com elevado poder de compra, com ambientes propícios para economia de escala, porém, foram observados elevados indicadores de massa salarial da indústria de transformação, sugerindo certa dependência desse tipo de indústria, provavelmente explicada por concentrar a maior parte dela.

As Indústrias Tradicionais (QLTRAD) foram, sem dúvida, as atividades mais dispersa no Estado de Minas. Por exemplo, a fabricação de produtos alimentícios e fabricação de bebidas são vistas em praticamente toda Minas Gerais, tendo se destacado Nanuque (Mucuri), Ituiutaba e Frutal (Triângulo), e Nanuque (Mucuri) na primeira atividade, e Salinas e Januária (Norte de Minas) na segunda. A fabricação de produtos têxteis, confecção de artigos do vestuário e acessórios, fabricação de produtos de madeira, fabricação de móveis também se mostraram amplamente diversificadas. As indústrias que indicaram um nível maior de concentração foram a fabricação de produtos do fumo em Uberlândia (Triângulo), a preparação de couros e fabricação de artefatos de couro artigos para viagem e calçados concentradas basicamente em Divinópolis, Formiga, Oliveira e Pium-í (Oeste), São João Del Rei (Campo das Vertentes), Andrelândia, São Sebastião do Paraíso e Passos (Sul de Minas), e ainda a fabricação de produtos diversos e a fabricação de produtos de borracha e de material plástico em Itajubá, Santa Rita do Sapucaí, São Sebastião do Paraíso, Pouso Alegre e São Lourenço, novamente no Sul-Mineiro. Denotase, que nas indústrias tradicionais estão os setores intensivos em trabalho, que de modo geral, demandam baixa qualificação da força de trabalho e se constituem em locais com baixos salários.

Finalmente, é possível perceber no cenário econômico-industrial de Minas Gerais uma diversificação da estrutura produtiva. Nota-se que as indústrias weberianas e tradicionais manifestam maiores possibilidades de instalação em microrregiões menos desenvolvidas, apresentando-se como uma saída estratégica aos governos, que através de políticas industriais regionais podem direcionar essas indústrias com o objetivo de tornar as microrregiões mais atrativas, alavancando sua economia e cooperando para seu desenvolvimento. Compreende-se, entretanto, que as indústrias dinâmicas estão consideravelmente concentradas nas microrregiões mais desenvolvidas do Estado - representadas aqui por suas mesorregiões: Metropolitana de Belo Horizonte e Sul de Minas - áreas caracterizadas pela ampla oferta de serviços produtivos, força de trabalho qualificada e maior poder de compra no mercado, que representam vantagens potenciais das regiões favoráveis às economias de urbanização, contribuindo ainda para atestar o desenvolvimento concentrado e a tese do desenvolvimento poligonal que privilegiam a região Centro-Sul do País.

\section{REFERÊNCIAS BIBLIOGRÁFICAS}

BETARELLI JUNIOR, A. A.; SIMÕES, R. F. A dinâmica setorial e os determinantes locacionais das microrregiões paulistas. Economia Aplicada, v. 15, n. 4, p. 641-670, 2011.

CANO, W. Desconcentração Produtiva Regional do Brasil 1970-2005. São Paulo: Editora Unesp, 2008. 
DINIZ, C. C. Desenvolvimento Poligonal no Brasil: Nem Desconcentração. Belo Horizonte: Nova Economia, v. 3, n. 1, 1993.

DINIZ, C. C. A dinâmica regional recente da economia brasileira e suas perspectivas. Instituto de Pesquisa Econômica Aplicada (IPEA). Brasília: Serviço Editorial, 1995.

DINIZ, G. F. C. Indústria mineira: mudanças estruturais e aglomerações territoriais. Dissertação de Mestrado. Porto Alegre: 2010.

ERBER, F. S. O padrão de desenvolvimento industrial e tecnológico e o futuro da indústria brasileira. Revista de Economia Contemporânea, v. 5, p. 179-206, 2001.

FEGER, J. E.; ETGES, V. E.; ROSSETTO, A. M. Limites de Regionalizações Para Elaboração de Estratégias Para o Desenvolvimento Regional. GESTÃO. Revista Eletrônica de Gestão Organizacional, v. 8, n. 2, 2010.

FERNANDES, C. L. L.; OLIVEIRA, F. A. Características e evolução recente da economia em Minas Gerais. In: As Muitas Minas: ensaios sobre a economia mineira. Fabrício Augusto de Oliveira; Wilson Benício Siqueira (ORGANIZADORES). Belo Horizonte: Conselho Regional de Economia Mineira, Minas Gerais, 2010.

FIGUEIREDO, A. T. L. Padrão Locacional Especializações Regionais da Indústria Mineira. Dissertação de Mestrado. Belo Horizonte: CEDEPLAR/UFMG, 1998.

FIGUEIREDO, A. T. L.; DINIZ, C. C. Distribuição regional da indústria mineira. Nova economia, v. 10, n. 2, 2000.

FIRME, V. A. C.; SIMÃO FILHO, J. Análise do crescimento econômico dos municípios de minas gerais via modelo MRW (1992) com capital humano, condições de saúde e fatores espaciais, 1991-2000. Economia Aplicada, v. 18, n. 4, p. 679-716, 2014.

FOCHEZATTO, A.; VALENTINI, P. J. Economias de aglomeração e crescimento econômico regional: um estudo aplicado ao Rio Grande do Sul usando um modelo econométrico com dados de painel. Revista Economia, 2010.

GODOY, M. M.; BARBOSA, D. H. D.; BARBOSA, L. S. Da arte de conhecer as doenças: o diagnóstico da economia mineira de 1968 e o planejamento do desenvolvimento de Minas Gerais. Nova Economia, v. 20, n. 2, p. 343-388, 2010.

IBGE. Instituto Nacional de Geografia e Estatística. Localização Geográfica: mesorregiões e microrregiões. Brasil: IBGE, 2014. Disponível em: $<$ https://www.mg.gov.br/governomg/portal/c/governomg/conheca-minas/geografia/5669-localizacaogeografica/69547-mesorregioes-e-microrregioes-ibge/5146/5044> Acesso em: 13 mar. 2016.

LIMA, J. F. et al. Análise regional das mesorregiões do estado do Paraná no final do século XX. Análise Econômica, v. 24, n. 46, 2006.MELLO, M. P.; PETERNELLI, L. A. Conhecendo o R: uma visão mais que estatística. Viçosa, MG: Editora UFV, 2013.

NEGRI, B. Concentração e desconcentração industrial em São Paulo (1880-1990). Tese de Doutorado. Campinas: UNICAMP, 1996.

NOGUEIRA JÚNIOR, R. P. As desigualdades inter-regionais no estado de Minas Gerais, com enfoque no setor industrial. In: As Muitas Minas: ensaios sobre a economia mineira. Fabrício Augusto de Oliveira; Wilson Benício Siqueira (ORGANIZADORES). Belo Horizonte: Conselho Regional de Economia Mineira, Minas Gerais, 2010.

PAUlA, R. Z. A. Percalços da industrialização: o caso de Minas Gerais. Dissertação de Mestrado. Campinas: SP: 2001.

PDMI. PLANO MINEIRO DE DESENVOLVIMENTO INTEGRADO. GOVERNO DO ESTADO DE MINAS GERAIS. PDMI - 2003/2020. Belo Horizonte, 2003.

PDMI. PLANO MINEIRO DE DESENVOLVIMENTO INTEGRADO. GOVERNO DO ESTADO DE MINAS GERAIS. PDMI - 2011/2030. Belo Horizonte, 2011.

RELATÓRIO SOBRE OS IMPACTOS DA MINERAÇÃO E AS MUDANÇAS NO CONTEXTO URBANO DE CONCEIÇÃO DO MATO DENTRO-MG. Projeto Internacional de Pesquisa Cidade e Alteridade. RELATÓRIO FINAL. Belo Horizonte, 2014. 
RESENDE, A. V. A indústria de bens de capital de Minas Gerais: oportunidades e entraves ao seu desenvolvimento. Tese de Doutorado. Campinas: UNICAMP, 1994.

SAMPAIO, D. P. Reestruturação produtiva regional no Brasil: uma caracterização da indústria com base em um indicador de densidade das cadeias produtivas (1996-2007). Dissertação de Mestrado. Campinas: UNICAMP, 2011.

SARTI, F.; HIRATUKA, C. Desenvolvimento industrial no Brasil: oportunidades e desafios futuros. Campinas: UNICAMP, Instituto de Economia da Unicamp, 2011.

SOBRAL, B. L. B. Desconcentração produtiva regional no Brasil: analise do estado do Rio de Janeiro: 1970/2006. Dissertação de Mestrado. Campinas: UNICAMP, 2007.

SOUZA, N. J. Desenvolvimento Regional. São Paulo: Atlas, 2009.

SOUZA, R. M.; PEROBELLI, F. S. Mudanças estruturais da economia mineira e do restante do Brasil: uma análise de insumo-produto para o período 1996-2003. Nova Economia, v. 19, n. 3, p. 407-441, 2009.

VIEIRA, D. J. Finanças públicas e desenvolvimento econômico em Minas Gerais: as implicações da renegociação da dívida para as políticas de fomento estadual. Dissertação de Mestrado. Campinas: UNICAMP, 2006. 